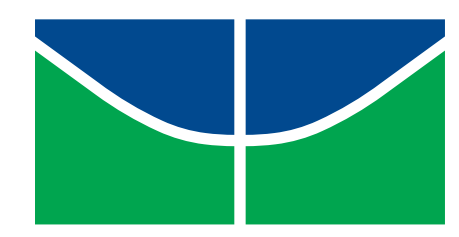

\author{
Universidade de Brasília \\ Instituto de Ciências Exatas \\ Departamento de Matemática
}

Aprendizagem Ativa e Colaborativa: uma proposta de uso de metodologias ativas no ensino da matemática

por

Thiago Yamashita Paiva

Brasília, 2016 


\section{Thiago Yamashita Paiva}

Dissertação apresentada ao Departamento de Matemática da Universidade de Brasília, como parte dos requisitos para a obtenção do grau de

\section{Mestre}

Orientador: Prof. Dr. Mauro Luiz Rabelo

Brasília

2016 
Ficha catalográfica elaborada automaticamente, com os dados fornecidos pelo(a) autor(a)

Paiva, Thiago Yamashita

Aprendizagem Ativa e Colaborativa: uma proposta de uso de metodologias ativas no ensino da matemática / Thiago Yamashita Paiva; orientador Mauro Luiz Rabelo. -- Brasília, 2016.

$55 \mathrm{p}$.

Dissertação (Mestrado - Mestrado Profissional em Matemática) -- Universidade de Brasília, 2016.

1. Aprendizagem pelos Colegas. 2. Aprendizagem Ativa e Colaborativa. 3. Metodologias ativas. I. Rabelo, Mauro Luiz, orient. II. Título. 


\title{
Aprendizagem Ativa e Colaborativa: Uma proposta de uso de metodologias ativas no ensino da matemática
}

$$
\text { por }
$$

\section{THIAGO YAMASHITA PAIVA}

\begin{abstract}
Dissertação apresentada ao Departamento de Matemática da Universidade de Brasília, como parte dos requisitos "Programa" de Mestrado Profissional em Matemática em Rede Nacional - PROFMAT, para obtenção do grau de
\end{abstract}

\section{MESTRE}

Comissão Examinadora:
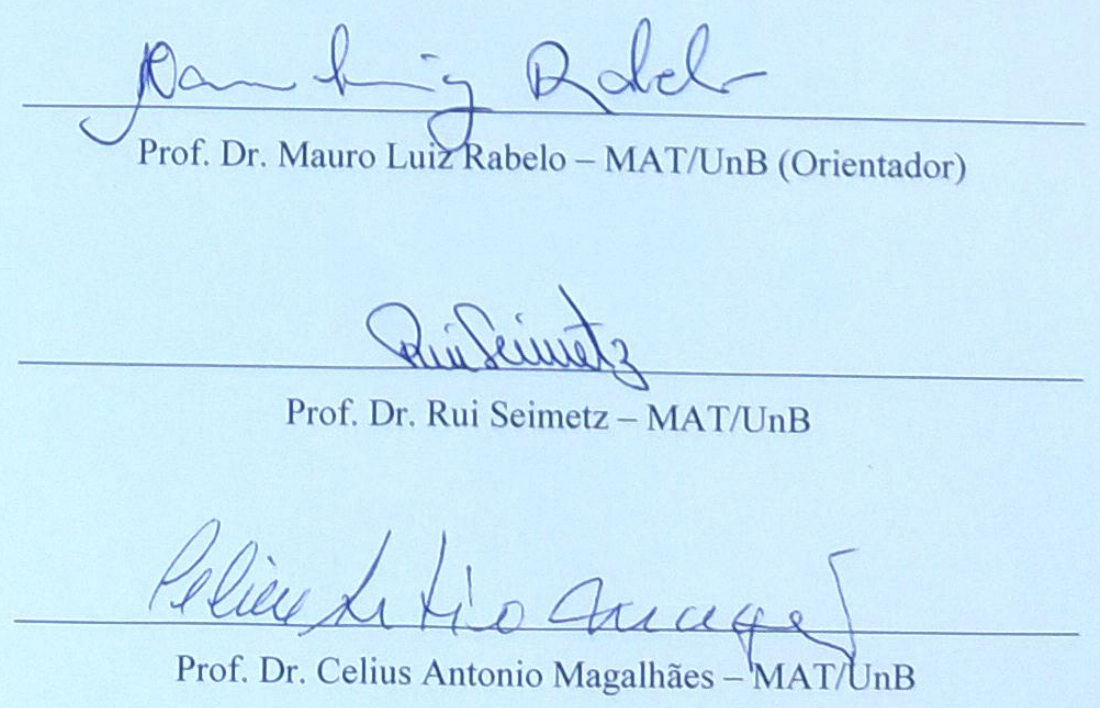

\footnotetext{
* O autor foi bolsista CAPES durante a elaboração desta dissertação
} 
"Filho, se você parar de aprender, logo esquecerá o que sabe" Pv 19:27 Bíblia Sagrada NTLH 


\section{Agradecimentos}

Agradeço a Deus pelas infindas bênçãos concedidas nesses dois últimos anos em todas as áreas de minha vida.

À minha mãe e meu pai pelos princípios e valores que me foram passados e que me fizeram chegar tão longe.

À minha esposa Marta Fernandes Yamashita pelo apoio durante todo o mestrado e pela imensa paciência e compreensão nesses últimos meses.

Aos professores Mauro Luiz Rabelo e Rui Seimetz dos quais tive o privilégio de ser aluno e que tanto na graduação quanto no mestrado me serviram de exemplo e inspiração, mudando minha visão sobre o ensino-aprendizagem de matemática.

Aos meus amigos André Marcelino Marques e Fabio Henrique Gomes que juntos conseguimos vencer todas as barreiras que apareceram durante o mestrado além de criar um grande laço de amizade.

Aos meus companheiros da turma do PROFMAT pelos momentos de estudo, compartilhando informações e dividindo experiências assim como nos momentos de confraternizações e alegria.

Em especial o programa do PROFMAT, que através da CAPES e da SBM, disponibilizaram essa formação acadêmica que muito contribuiu para minha carreira. 


\section{Resumo}

Muitos professores de matemática, da educação básica até o nível superior, estão preocupados em procurar métodos alternativos de ensino, mas abandonar a aula expositiva parece ser uma tarefa muito complicada, pois nem sempre é fácil romper com a lei da inércia, que nos impulsiona a continuar atuando da mesma forma, repetindo modelos pedagógicos centenários. Com o objetivo de contribuir com essa discussão no âmbito da atuação do professor de matemática, este trabalho apresenta uma breve descrição sobre algumas metodologias de aprendizagem ativas e colaborativas que estão sendo utilizadas em Universidades e escolas do Brasil e de outros países. Um enfoque maior é dado ao peer instruction ou aprendizagem pelos colegas (ApC). Inclui-se também um relato de observação de uma aula de matemática realizada com a técnica ApC em uma escola de ensino médio da rede pública do Distrito Federal.

Palavras-chave: Metodologias ativas; Aprendizagem Ativa e Colaborativa; Aprendizagem pelos Colegas, peer instruction. 


\begin{abstract}
Many math teachers, from basic education to higher education, are concerned to seek alternative methods of teaching, but leave the lecture seems to be a very complicated task, because it is not always easy to break the law of inertia, which impels us to continue acting in the same way, repeating centenarians pedagogical models. In order to contribute to this discussion in the role of the maths teacher, this paper presents a brief description of some active and collaborative learning methodologies that are being used in universities and schools in Brazil and other countries. A greater focus is given to the peer instruction. Also includes an observation report of a math class conducted with peer instruction technique in a public high school of Brazilian Federal District.
\end{abstract}

Keywords: Active Methodologies; Active and collaborative learning; Peer instruction. 


\section{Sumário}

$\begin{array}{ll}\text { Introdução } & 1\end{array}$

\begin{tabular}{ll}
\hline Motivação & 3
\end{tabular}

$\begin{array}{ll}\text { Metodologia } & 5\end{array}$

$\begin{array}{lll}1 & \text { Avaliação para a aprendizagem } & 6\end{array}$

1.1 Tipos de Avaliação . . . . . . . . . . . . . . . . . . . . . . . . 7

1.2 Histórico do Conceito de Avaliação segundo a Lei brasileira . . . . . . 10

1.3 Avaliação como Mediação . . . . . . . . . . . . . . . . . . . . 13

$\begin{array}{lll}2 & \text { Aprendizagens Ativas } & 15\end{array}$

\begin{tabular}{lll}
\hline 3 & Metodologias Ativas & 19
\end{tabular}

$3.1 \quad$ Aprendizagem Baseada em Problemas - ABP . . . . . . . . . . . . . . 19

$3.1 .1 \quad$ Elaboração dos Problemas . . . . . . . . . . . . . . . . . . . 21

3.1 .2 Vantagens e desvantagens da ABP . . . . . . . . . . . . . 21

3.2 Modelagem Matemática $\quad \ldots \ldots \ldots \ldots$

$3.2 .1 \quad$ Etapas da Modelagem Matemática . . . . . . . . . . . . . . . . 24

3.2 .2 Vantagens da Modelagem Matemática . . . . . . . . . . . . . . 25

$3.2 .3 \quad$ Desvantagens da Modelagem Matemática . . . . . . . . . . . . . 25

3.3 Aprendizagem pelos Colegas . . . . . . . . . . . . . . . . . 26

3.4 Just-in-Time-Teaching-Ensino sob Medida (EsM) . . . . . . . . . . 32

3.5 EsM em conjunto com ApC . . . . . . . . . . . . . . . . . 34

4 Proposta de uma aula sobre função afim com o uso da Aprendizagem

pelos Colegas 35

4.1 Preparação do material teórico . . . . . . . . . . . . . . . . . . . . . 35

4.2 Confecção dos Flashcards . . . . . . . . . . . . . . . . . . . . . . . 36

4.3 Teste de Leitura . . . . . . . . . . . . . . . . . . . . . . . . . . 37 
$4.4 \quad$ Elaboração das questões conceituais: . . . . . . . . . . . . . . . . . 38

5 Aplicação da ApC em sala de aula 43

$\begin{array}{lll}6 & \text { Considerações Finais } & 47\end{array}$

\begin{tabular}{|ll}
\hline A Material disponibilizado aos alunos & 53
\end{tabular} 


\section{Lista de Figuras}

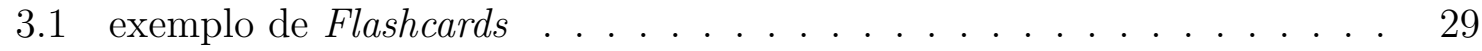

3.2 exemplo de um clicker . . . . . . . . . . . . . . . . . . . 30

3.3 Diagrama de funcionamento da aprendizagem pelos colegas. Em destaque está a parte crucial do método, a interação entre os alunos. . . . . . 31

3.4 Linha do tempo das metodologias aprendizagem pelos colegas e ensino sob medida . . . . . . . . . . . . . . . . . . . . . . . 32

4.1 Esquema de montagem com palitos. . . . . . . . . . . . . . 40

4.2 Exemplo de mesas sendo juntadas em um restaurante. . . . . . . . . . 42 


\section{Lista de Tabelas}

5.1 Respostas das aplicações $\ldots \ldots \ldots \ldots$. . . . . . . . . . . . 43 


\section{Introdução}

$\mathrm{O}$ ato de ensinar tem-se tornado cada vez mais complexo. O professor, antes o centro das atenções, disputa seu posto de única fonte de conhecimento com a tecnologia, a internet, as videoaulas, os tedtalks, entre outros recursos hoje acessíveis facilmente através de um computador ou celular. Uma vez que, em geral, as tecnologias não estão inseridas diretamente nas atividades escolares, elas se tornam meio de descontração para os alunos. Os alunos estão cada vez mais inseridos nas tecnologias e redes sociais. A geração atual é digital, enquanto as escolas, em sua esmagadora maioria, ainda continuam "analógicas". Segundo Prensky (2001):

Eles passaram a vida inteira cercados por e utilizando computadores, videogames, reprodutores de música digital, câmeras de vídeo, celulares, e todos os outros brinquedos e ferramentas da era digital. [...] Jogos de computador, e-mail, internet, celulares e mensagens instantâneas são partes integrais de suas vidas.

(PRENSKY, 2001)

Chamados de "nativos digitais", os jovens e crianças de hoje preferem estar na frente de um computador ou celular, conectados, recebendo informações e interagindo com elas do que na frente de uma TV para assistir a um programa, onde não há interação. Na escola, o aluno precisa ficar entre quatro e cinco horas assistindo aulas, muitas vezes de forma passiva, sem interagir, apenas escutando os professores, o que se torna uma difícil tarefa. Talvez seja por esse motivo que os alunos são tão dispersos, pois tudo que há ao seu redor, disponível fora do espaço escolar, parece mais interessante do que a aula. Segundo Rabelo (2013):

Nesse cenário em que os nascidos digitais chegam à escola, será preciso repensar o modelo de educação praticado, liberando os estudantes de um ambiente fixo de aprendizagem, incorporando 
materiais pedagógicos cada vez mais criativos, aceitando as incertezas, compartilhando experiências, promovendo e incentivando a autoaprendizagem, explorando a potencialidade das redes virtuais de relacionamento, buscando tecnologias muitas vezes invisíveis ao docente, mas que propiciam a aprendizagem dos estudantes. (RABELO, 2013, p. 235)

Naturalmente, os professores não podem mais fechar os olhos para esse novo contexto e continuarem repetindo indefinidamente o modelo tradicional de aula de transmissão-recepção e, assim, o debate sobre novas metodologias de ensino e aprendizagem ganha cada vez mais força no Brasil e no mundo. Com essa preocupação em mente, este trabalho abordará, além de uma reflexão sobre avaliação e aprendizagem ativa, uma busca bibliográfica sobre as principais metodologias ativas como Problem Based Learning (PBL), Modelagem Matemática, Peer Instrucion ou Aprendizagem pelos Colegas(ApC) e Just-In-Time Teaching (JITT ou Ensino sob Medida - EsM). Uma proposta de aula com a metodologia da aprendizagem pelos colegas é apresentada ao final para demonstrar que é possível aplicá-la em salas de aula de ensino médio. 


\section{Motivação}

Decidi escolher essa temática pois na minha atuação como docente tenho percebido o grande desinteresse dos alunos em relação à matemática e escuto frequentemente o mesmo comentário de meus colegas professores de outras disciplinas.

Diante da grande dificuldade dos alunos em relação à matemática e aos maus índices de rendimento evidenciados em avaliações tanto no nível da sala de aula quanto nas avaliações de sistemas feitas pelo Ministério da Educação, torna-se imperioso buscar alternativas metodológicas para tentar motivar os estudantes e tentar sanar os problemas de aprendizagem dos conhecimentos básicos da matemática. A preocupação em fazer somente aquilo que vale alguma pontuação, entre outras atitudes como reservar pontuação para organização do caderno, tem feito com que os estudantes transfiram o foco da aprendizagem para a obtenção da nota, subvertendo o papel da avaliação, que deveria ser um instrumento de favorecimento da aprendizagem e não apenas funcionar como um estímulo, um "pagamento" por ter feito isso ou aquilo.

Mesmo sabendo que o professor deve ter o papel de mediador, eu repeti os modelos que vivenciei como estudante ao longo de minha vida acadêmica e comecei também a ministrar apenas aulas expositivas. Segundo ouvi do professor Mauro Rabelo, durante a disciplina de Avaliação Educacional, no PROFMAT, isso é o "mimetismo pedagógico": a gente imita alguns modelos que vivenciamos como alunos. Assim, um dos motivos que justificam eu não mudar, era que eu só conhecia esse tipo de aula em matemática.

A prática das aulas onde o professor é o transmissor e o aluno o receptor, fez com que o ato de copiar algo do quadro, fazer exercícios repetitivos ou escrever um resumo, faz o aluno se sentir mais confortável do que desenvolver atividades que exijam reflexão, discussão e exposição de ideias. Nessa atitude passiva, ninguém se expõe, o professor fica na postura daquele que sabe, que detém o conhecimento, e o aluno "finge" que aprende. Infelizmente é uma herança da educação tecnicista, que já dura décadas, ou pelo menos uma centena de anos.

Aos poucos fui percebendo como a aula expositiva era pobre em mostrar ao 
professor se os seus alunos estão entendendo o que ele está ensinando ou não. Comecei a ficar perturbado com a rotina de entrar e sair da aula sem ter a certeza se meus estudantes estavam, de fato, compreendendo aquilo que eu estava "tentando ensinar". Sempre era preciso esperar o resultado de uma prova para constatar, com pesar, que o resultado era pífio. A frustração era constante. Sentia que não estava cumprindo com minha missão como educador. Afinal, me formei como professor, escolhi essa profissão porque acredito na transformação dos indivíduos por meio da educação.

Durante a escolha do tema, meu orientador comentou sobre o trabalho que estava sendo desenvolvido na UnB por um professor de Cálculo, que procura maneiras diferentes para motivar seus estudantes para o aprendizado dessa disciplina. Mais especificamente, ele me indicou o professor Ricardo Fragelli, docente da Faculdade UnB Gama, que utiliza a Metodologia dos 300 em suas aulas. Nesse método são criados grupos colaborativos, nos quais alunos que tiraram as melhores notas no primeiro teste passam a ajudar os colegas que obtiveram desempenho insuficiente. Comecei, então, a me interessar para entender melhor como funcionam metodologias desse tipo e, pesquisando mais sobre outras metodologias ativas, encontrei a Peer Instruction, ou Aprendizagem pelos Colegas (ApC). Na ApC, o aluno lê grande parte do material teórico em casa e, em sala, o professor, durante breves estímulos e explicações iniciais, dependendo das respostas dos alunos, propõe a discussão entre os pares sobre a resolução de uma questão cuidadosamente escolhida ou elaborada por ele.

Este trabalho não tem como objetivo condenar a aula expositiva, mas proporcionar opções para que a prática do docente seja mais rica e abrangente e proporcionar conhecimento para que o professor consiga distinguir quando é mais efetivo usar uma metodologia ativa e quando é melhor usar uma aula expositiva.

Como afirma Libâneo (1998):

O ensino exclusivamente verbalista, a mera transmissão de informações, a aprendizagem entendida somente como acumulação de conhecimentos, não subsistem mais. Isso não quer dizer abandono dos conhecimentos sistematizados da disciplina nem da exposição de um assunto. O que se afirma é que o professor medeia a relação ativa do aluno com a matéria.

Embora direcionado para a área de matemática, os temas aqui abordados podem ser aplicados em qualquer área do conhecimento. 


\section{Metodologia}

Este trabalho está organizado primeiramente numa introdução sobre avaliação, resgatando o verdadeiro sentido da avaliação de reorientar a prática pedagógica, o que será muito usado nas metodologias ativas. Em seguida, será apresentado o conceito de aprendizagem ativa e colaborativa.

Uma pesquisa bibliográfica sobre as principais metodologias ativas comporá a parte principal do trabalho, com grande enfoque para a metodologia aprendizagem pelos colegas.

A grande dificuldade dos professores das áreas de exatas, especialmente da matemática, de deixar a aula expositiva e experimentar outras experiências fez a Aprendizagem pelos Colegas - ApC ser escolhida como ponto principal do trabalho. Assim, é apresentada a estrutura de funcionamento de uma proposta de aula com a ApC, escolhendo-se um tema específico da matemática, usualmente ensinado no ensino médio, e o relato da observação feita por este pesquisador de uma aula realizada em uma escola pública do Distrito Federal, na qual, pela primeira vez, os alunos tiveram um contato com esse tipo de metodologia. 


\section{Capítulo 1}

\section{Avaliação para a aprendizagem}

A avaliação é uma tarefa didática, formal ou não, que deve acompanhar todos os passos do processo de ensino e aprendizagem. É uma parte integrante e indissociável do trabalho docente. Através dela, o professor vai analisar os progressos obtidos pelos alunos a fim de reorientar o seu trabalho pedagógico conforme necessário. Dessa forma, a avaliação está cumprindo o papel de avaliação para a aprendizagem. Quando não há mudança nas práticas pedagógicas, a avaliação cumpre apenas o papel de classificar, e, na maioria das vezes, de excluir.

Uma avaliação sem intencionalidade perde o sentido tanto para o professor quanto para os alunos. Se torna uma carga para ambos, como afirmam Jorba e Sanmartí (2003, p. 24): "avaliar é (...) a prática pedagógica que menos motiva os professores e mais os aborrece. Ao mesmo tempo, para os alunos, a avaliação é a atividade mais temida e menos gratificante".

Segundo Hoffmann (2007), em encontros feitos com professores da educação infantil até a universidade, estes demonstram concepções de avaliação como estática e frenadora, de caráter classificatório e fundamentalmente sentencivo. Atrelado à ideia de julgamento, a avaliação perde o caráter de auxiliar a aprendizagem para fazer do aluno um mero reprodutor de informações e não um ser crítico. Libâneo também cita como problema a utilização da avaliação como meio de intimidação e ameaça, como forma de controle, assim como o uso da avaliação como recompensa aos bons "alunos" e punição aos desinteressados, frisando ainda:

A avaliação é uma tarefa complexa que não se resume à realização de provas e à atribuição de notas. A mensuração apenas proporciona dados que devem ser submetidos a uma apreciação qualitativa. A avaliação, assim, cumpre funções pedagógico-didáticas, de diagnóstico e controle em relação às quais se recorrem a instrumentos de verificação do rendimento escolar. (Libâneo, 1994, p.195) 


\subsection{Tipos de Avaliação}

O autor português Domingos Fernandes (2006) nos aponta em seu belíssimo artigo "Para uma teoria de avaliação formativa", as dificuldades de se teorizar sobre os diversos conceitos de avaliação, uma vez que essa disciplina não é como a matemática, uma ciência exata. Segundo ele:

A avaliação não é uma disciplina exacta e, muito provavelmente, nunca o poderá vir a ser, por razões que atrás já se aduziram. A avaliação que se faz nas salas de aula também não é uma questão técnica ou uma mera questão de construção e utilização de instrumentos, nem um exercício de encaixar conhecimentos, capacidades, atitudes ou motivações dos alunos numa qualquer categoria com o auxílio de uma qualquer taxonomia. A avaliação é um processo desenvolvido por e com seres humanos para seres humanos, que envolve valores morais e éticos, juízos de valor e problemas de natureza sociocognitiva, sociocultural, antropológica, psicológica e também política. No entanto, também parece que, não sendo matéria exacta, pode e deve basear-se em sólidas e significativas evidências e, neste sentido, não será uma simples questão de convicção, crença ou persuasão. (FERNANDES, 2006, p. 36)

Assim, Fernandes nos ensina que a avaliação envolve valores morais e éticos, juízos de valor e muitas outras dimensões. Trata-se, então, de algo complexo, mas que nem sempre é tratada nessa complexidade pelos professores. Isso também é apontando por Rabelo (2013), quando diz que:

A avaliação da aprendizagem é um tema que, além de representar uma preocupação quase que universalmente presente nos debates sobre educação, revela uma unanimidade: sua operacionalização pertence à esfera do complexo. Isso é consequência natural do fato de que o processo de formação do ser humano reflete todas as possibilidades e todos os matizes de seres que somos. (RABELO, 2013, p. 224)

Assim, o tema da avaliação, pela sua complexidade, poderia ocupar grande parte deste trabalho, mas não é nosso foco principal. Apenas desejamos pontuar algumas diferenças entre os tipos atualmente praticados. Ao categorizar os tipos, Fernandes (2006) subdivide a avaliação em várias categorias e subcategorias, tentando clarificar o significado da avaliação formativa. Trata-se de excelente fonte para quem desejar aprofundar os conhecimentos sobre o tema. Para simplificar, vamos apenas mencionar os três tipos mais comuns tratados na literatura: diagnóstica, formativa e somativa. 
Segundo Luckesi (2002), o pesquisador que utilizou as denominações - avaliação diagnóstica, formativa e somativa - foi Benjamin Bloom.

Por avaliação diagnóstica, ele compreendeu a investigação das razões dos fracassos na prática educativa em qualquer momento do seu percurso (início, meio e fim); por formativa, ele compreendeu a prática avaliativa realizada enquanto uma atividade se executa; ela subsidiaria a "formação" (construção) dos resultados; por avaliação somativa, ele compreendeu a avaliação final, que permite uma certificação da atividade, expressando, de certa forma, sua validação (seria um ajuizamento final sobre a atividade, tendo por base os seus resultados). (LUCKESI, 2002)

Em geral, considera-se avaliação diagnóstica aquela que acontece no início do processo, antes do planejamento e que tem a função de adaptar o planejamento às necessidades do aluno. No entanto, para Luckesi,

qualquer prática avaliativa é diagnóstica, ocorra em que momento for da ação, no sentido de que toda prática avaliativa tem dois pontos básicos: (1) investigar sobre o desempenho de alguma coisa, projeto, instituição ou pessoa (o que está ocorrendo e as razões pelas quais o que está ocorrendo, está ocorrendo), atribuindo-lhe uma qualidade, e, (2) em segundo lugar, proceder uma intervenção, tendo em vista o redirecionamento da ação, instituição ou pessoa. (LUCKESI, 2006)

Villas Boas (2006) comenta que na educação escolar brasileira, ainda se encontram fortes traços da avaliação classificatória, seletiva e excludente. Segunda a autora,

para dar nota e para aprovar ou reprovar os alunos. As práticas avaliativas escolares têm, cada vez mais, se inspirado na competição presente nas atividades sociais. Não é à toa que se diz com frequência: professor nota 10; show nota 10; promoção nota 10 (de loja); gás nota 10 etc. Como a avaliação está presente em todas as situações da vida, é natural que haja influência mútua entre a que se realiza na escola e a que acontece no nosso dia-adia. (VILLAS BOAS, 2006, p. 77-78)

Para ela, a avaliação classificatória é uma das manifestações da avaliação somativa na escola e constitui a denominada "avaliação classificatória", termo que não aparece usualmente na literatura internacional sobre avaliação. Villas Boas comenta 
que, em um artigo sobre avaliação formativa, que pode ser considerado clássico, tal a sua importância e o uso que dele tem sido feito, o professor australiano Royce Sadler (1989, p. 120) afirma que avaliação somativa é a que mostra o balanço do desempenho do aluno ao final de um período, geralmente com o propósito de certificação ou classificação. Ele define que a avaliação somativa

apresenta o balanço do desempenho do aluno ao final de um período de estudos, geralmente com o propósito de certificação [...]. É empregada para medir o que foi aprendido ao final de determinado período; para promover os alunos; para assegurar que eles alcancem os padrões de desempenho estabelecidos para conclusão de cursos, para exercer certas ocupações ou para selecionar os que prosseguirão os estudos.(VILLAS BOAS, 2006, p. 78)

Ainda segundo esse autor, "o que diferencia a avaliação somativa da formativa é o propósito e o efeito, e não o momento da sua realização", ou até mesmo a sua forma.

Para Perrenoud (1998), avaliação formativa é toda prática de avaliação contínua que tenha como objetivo contribuir para melhorar as atividades em curso. Villas Boas (2006, p.78) acrescenta que na avaliação que cumpre sua função formativa é aquela pela qual

os professores analisam, de maneira frequente e interativa, o progresso dos alunos, para identificar o que eles aprenderam e o que ainda não aprenderam, para que venham a aprender, e para que reorganizem o trabalho pedagógico. Essa avaliação requer que se considerem as diferenças dos alunos, se adapte o trabalho às necessidades de cada um e se dê tratamento adequado aos seus resultados. Isso significa levar em conta não apenas os critérios de avaliação, mas, também, tomar o aluno como referência. A análise do seu progresso considera aspectos tais como: o esforço por ele despendido, o contexto particular do seu trabalho e as aprendizagens adquiridas ao longo do tempo. Consequentemente, o julgamento da sua produção e o feedback que lhe será oferecido levarão em conta o processo de aprendizagem por ele desenvolvido, e não apenas os critérios de avaliação. As circunstâncias individuais devem ser observadas se a avaliação pretende contribuir para o desenvolvimento da aprendizagem e para o encorajamento do aluno. A avaliação formativa seria desencorajadora para muitos alunos que enfrentam fracasso se fosse baseada exclusivamente em critérios. A combinação da 
avaliação baseada em critérios com a consideração das condições do aluno fornece informações importantes e é consistente com a ideia de que a avaliação formativa é parte essencial do trabalho pedagógico. A identificação de problemas ou dificuldades que os alunos possam ter pode ser feita somente por meio dessa combinação de informações (HARLEN; JAMES, 1997, p. 370, apud VILLAS BOAS, 2006, p.78).

Fica evidente nas palavras da autora a complexidade que envolve o processo de avaliação formativa, o que explica, em parte, a proliferação da avaliação classificatória, formativa, no meio acadêmico, em especial entre os professores da área de matemática. Não é fácil acompanhar de perto cada aluno, adaptando a avaliação aos tempos de aprendizagem de cada um. Rabelo (2013) expõe que, diante do desafio de se praticar uma avaliação que esteja a serviço das aprendizagens, o professor precisa:

- ter consciência das limitações dos instrumentos de avaliação produzidos para dar conta das diversidades e que respeitem os tempos de aprendizagem de cada aluno;

- buscar maneiras de utilizar de modo eficaz as novas tecnologias em favor da aprendizagem;

- reavaliar e regular constantemente sua própria prática;

- deixar espaço para o dialogo e a participação dos estudantes em sala, evitando falar o tempo todo;

- procurar sempre motivar e dar sentido ao conteúdo trabalhado em sala e explorados nas avaliações;

- auxiliar no processo de desenvolvimento da autonomia dos estudantes;

- fazer devolutivas, ou feedbacks, para os estudantes com clareza e simplicidade de informação. (RABELO, 2013, pp.232-233)

\subsection{Histórico do Conceito de Avaliação segundo a Lei brasileira}

A concepção de avaliação segundo a Lei brasileira também mudou ao longo dos anos, o que será observado segundo o breve resgate histórico feito a seguir, em especial na Lei de Diretrizes e Bases da Educação Nacional (LDB), em suas diversas versões. Retornando ao ano de 1961, apontamos o seguinte excerto da Lei n.o 4.024: 
LEI N. 4.024, DE 20 DE DEZEMBRO DE 19611 Art. 39. A apuração do rendimento escolar ficará a cargo dos estabelecimentos de ensino, aos quais caberá expedir certificados de conclusão de séries e ciclos e diplomas de conclusão de cursos.

$\S 1^{\circ} \mathrm{Na}$ avaliação do aproveitamento do aluno preponderarão os resultados alcançados, durante o ano letivo, nas atividades escolares, asseguradas ao professor, nos exames e provas, liberdade de formulação de questões e autoridade de julgamento.

$\S 2^{\circ}$ Os exames serão prestados perante comissão examinadora, formada de professores do próprio estabelecimento, e, se este for particular, sob fiscalização da autoridade competente.

A LDB de 1961 atribuía claramente ao professor a "autoridade de julgamento", o que certamente se coaduna com a visão preponderante ainda hoje do papel do docente como aquele que julga, sentencia, que tem a função de reprovar ou promover o aluno, utilizando a avaliação como um instrumento coercitivo. Isso explica em parte a predominância da avaliação somativa sobre a formativa e até mesmo a dificuldade da maioria de aceitar que a avaliação deveria estar tão-somente a serviço das aprendizagens dos estudantes.

Após dez anos, por intermédio da Lei n.o 5.692, a redação da lei toma a seguinte forma:

\section{LEI N. 5.692 - DE 11 DE AGOSTO DE 19712}

Art. 14. A verificação do rendimento escolar ficará, na forma regimental, a cargo dos estabelecimentos, compreendendo a avaliação do aproveitamento e a apuração da assiduidade.

$\S 1^{\circ} \mathrm{Na}$ avaliação do aproveitamento, a ser expressa em notas ou menções, preponderarão os aspectos qualitativos sobre os quantitativos e os resultados obtidos durante o período letivo sobre os da prova final, caso esta seja exigida.

$\S 2^{\circ} \mathrm{O}$ aluno de aproveitamento insuficiente poderá obter aprovação mediante estudos de recuperação proporcionados obrigatoriamente pelo estabelecimento.

Percebe-se um claro avanço em relação à Lei anterior, uma vez que o caráter processual da avaliação começa a aparecer no texto legal ao mencionar, no parágrafo primeiro do artigo 14 que "preponderarão os aspectos qualitativos sobre os quantitativos e os resultados obtidos durante o período letivo sobre os da prova final". Assim, o debate sobre a avaliação formativa começa a transparecer no texto legal, uma vez que, antes, a avaliação tinha um foco apenas somativo.

Com a nova legislação, aprovada em 1996, e vigente até hoje, fica bem mais claro a intenção de se dar uma "virada" nas funções e usos do processo avaliativo, 
aproximando-se cada vez mais do papel mais nobre da avaliação, que é o de favorecer as aprendizagens dos estudantes. Merece destaque o artigo 24, parágrafo V, transcrito a seguir.

\section{LEI N.9.394 - DE 20 DE DEZEMBRO DE 19963}

Art.24. Parágrafo V. A verificação do rendimento escolar observará os seguintes critérios:

a) avaliação contínua e cumulativa do desempenho do aluno, com prevalência dos aspectos qualitativos sobre os quantitativos e dos resultados ao longo do período sobre os de eventuais provas finais;

b) possibilidade de aceleração de estudos para alunos com atraso escolar;

c) possibilidade de avanço nos cursos e nas séries mediante verificação do aprendizado;

d) aproveitamento de estudos concluídos com êxito;

e) obrigatoriedade de estudos de recuperação, de preferência paralelos ao período letivo, para os casos de baixo rendimento escolar, a serem disciplinados pelas instituições de ensino em seus regimentos; 1

Nos critérios citados, percebe-se que o foco não é mais uma simples obtenção de nota, mas o aprendizado do aluno, inclusive proporcionando acelerações de estudos ou recuperações, caso necessário.

Essa mudança enfatiza que a Lei de Diretrizes e Bases da Educação Nacional, ao longo dos anos, se torna mais voltada para a avaliação ao longo do processo (avaliação formativa) ao invés da avaliação somente ao final do processo (avaliação somativa).

Já os Parâmetros Curriculares Nacionais afirmam que:

é importante que a Matemática desempenhe, equilibrada e indissociavelmente, seu papel na formação de capacidades intelectuais, na estruturação do pensamento, na agilização do raciocínio dedutivo do aluno, na sua aplicação a problemas, situações da vida cotidiana e atividades do mundo do trabalho e no apoio à construção de conhecimentos em outras áreas curriculares. [...] Os resultados expressos pelos instrumentos de avaliação, sejam

\footnotetext{
1 fontes:

1.<http://www.planalto.gov.br/ccivil_03/LEIS/L4024.htm> Acesso em: 27/02/2016.

2.<http://www2.camara.leg.br/legin/fed/lei/1970-1979/lei-5692-11-agosto-1971-357752-

publicacaooriginal-1-pl.html $>$ Acesso em: 27/02/2016.

3. <http://legis.senado.gov.br/legislacao/ListaTextoIntegral.action?id=75723> Acesso em:

$27 / 02 / 2016$.
} 
eles provas, trabalhos, postura em sala, constituem indícios de competências e como tal devem ser considerados. A tarefa do avaliador constitui um permanente exercício de interpretação de sinais, de indícios, a partir dos quais manifesta juízos de valor que lhe permitem reorganizar a atividade pedagógica. (PCN Matemática, 2000, pp. 25-29)

Ainda segundo Luckesi (1998, p 72-74), a avaliação é feita através de um processo que envolve: uma aferição dos resultados, transformação desses resultados em uma medida, e após isso em um resultado chamado de nota. Mas a avaliação não termina com a nota. A parte mais importante da avaliação é o que pode ser feito após esse resultado:

- um simples registro no Diário de classe;

- caso a nota seja insatisfatória, oferecer ao aluno uma oportunidade de que ele faça uma nova "aferição";

- trabalhar aquilo que os educandos precisam de fato aprender, levando em conta os desvios de aprendizagem observados na avaliação.

As duas primeiras atitudes não proporcionam acréscimo algum, ou quase nenhum, ao aprendizado. Por mais que uma nova avaliação com uma recuperação possa gerar uma aprendizagem, o foco não é a aprendizagem, mas sim a obtenção da nota. Infelizmente essas duas são as mais usadas na escola. A terceira, que estabelece uma verdadeira aprendizagem, é a mais rara.

Como afirma Luckesi (1998, p. 75), "a aferição da aprendizagem escolar é utilizada na quase totalidade das vezes, para classificar os alunos em aprovados e reprovados". O autor classifica essa forma de avaliação como meramente uma verificação, pois não há uma mudança em relação à prática pedagógica ao final do ano, ao final de um bimestre ou período escolar.

Nas metodologias a serem apresentadas nos próximos capítulos, se dará uma total importância à observação da avaliação com o objetivo principal de orientar a aprendizagem.

\subsection{Avaliação como Mediação}

A autora Hoffmann (2010) em sua perspectiva construtivista indica algumas ações mediadoras coerentes como oportunizar momentos para os alunos expressar suas ideias, oportunizar discussões entre os próprios alunos e através de tarefas individuais, tentar entender as razões das respostas dadas pelos alunos, de forma a entender em qual momento da aprendizagem eles estão. 
Com tamanha importância da interação entre iguais na teoria construtivista, a discussão entre os alunos se torna elemento chave no processo de ensino aprendizagem. O aluno compreende mais rápido aquilo que não tinha entendido com a discussão com um colega. É nesse ponto que se baseiam as metodologias ativas. O professor, assumindo a posição de mediador, provoca os alunos com situações-problemas de modo a desencadear discussões entre eles de modo que possa encontrar uma solução entre as alternativas dadas entre os alunos.

Assim, discussões em grupo são momentos que devem, isso sim, ser acompanhados pelo professor, alerta aos vários argumentos surgidos, prestando atenção para desencadear novas questões, mas nunca como elementos de avaliação individual.(HOFFMANN, 2010, p. 61)

Hoffmann também defende a utilização de discussões em pequenos grupos ao invés de trabalhos em grupos maiores, pois, nestes, a organização das ideias costuma ser de poucos ou de apenas um dos integrantes do grupo. 


\section{Capítulo 2}

\section{Aprendizagens Ativas}

Aprendizagem ativa é um conjunto de práticas pedagógicas centradas no aluno de forma que ele aprenda os conhecimentos propostos por meio da interação entre ele e os outros colegas, estimulando o pensamento crítico.

O estudo da aprendizagem ativa remonta ao século XVIII, quando alguns teóricos e professores começaram a fazer testes em várias disciplinas. Entretanto, as teorias de aprendizagens ativas ganharam maior força ao longo de vários movimentos como o da Escola Nova, no começo do século XX, com os trabalhos de Jean Piaget e Lev Vygotsky, nos anos 50, e a também a partir da Primeira Conferência Internacional sobre Aprendizagem Cooperativa em Tel Aviv, Israel, entre muitos outros marcos importantes.

O termo aprendizagem ativa engloba outros termos como aprendizagem colaborativa e aprendizagem cooperativa. Há uma discussão em relação ao significado dos termos Colaboração e Cooperação.

Dillenbourg (1999 apud Torres e Irala, 2004 p. 65) define de forma simples a aprendizagem colaborativa: "É uma situação na qual duas ou mais pessoas aprendem ou tentam aprender algo juntas".

$\mathrm{Na}$ colaboração, todos os participantes dos grupos de trabalho são responsáveis pelo sucesso ou não do grupo. Percebe-se aqui a ausência de hierarquia dentro de cada grupo.

Segundo Matthews (1995), a aprendizagem cooperativa tende a ser mais estruturada na sua abordagem à instrução em pequenos grupos do que na aprendizagem colaborativa.

Em linhas gerais, a diferença sutil entre o significado dos dois termos reside no fato de o processo de cooperação ser mais controlado pelo professor, enquanto que na colaboração, o aluno possui um papel mais ativo. (Torres e Irala, 2014, p. 68).

$\mathrm{Na}$ aprendizagem ativa, o aluno tem uma nova visão do professor. O professor não é mais aquele que ministra a aula enquanto o aluno somente assiste e copia. 
Nela, o aluno absorve os conteúdos por meio do desenvolvimento de atividades propostas pelo professor, executando junto com os outros colegas, enquanto o professor supervisiona e propõe novas discussões e desafios, conforme nos ensina Luckesi:

a aprendizagem ativa é aquela construída pelo educando a partir da assimilação ativa dos conteúdos socioculturais. Isso significa que o educando assimila esses conteúdos, tornando-os seus, por meio da atividade de internalização de experiências vividas. (LUCKESI, 2002, p.132).

A aula meramente expositiva está ultrapassada. O aluno não pode ser um repetidor de informações. O professor deve instigar o aluno a pensar, refletir, formar e expressar a sua própria opinião, sem precisar abandonar os conhecimentos particulares de cada disciplina.

O ensino exclusivamente verbalista, a mera transmissão de informações, a aprendizagem entendida somente como acumulação de conhecimentos, não subsistem mais. Isso não quer dizer abandono dos conhecimentos sistematizados da disciplina nem da exposição de um assunto, o que se afirma é que o professor medeia a relação ativa do aluno com a matéria, inclusive com os conteúdos próprios de sua disciplina, mas considerando os conhecimentos, a experiência e os significados que os alunos trazem à sala de aula (...) Ao mesmo tempo, o professor ajuda no questionamento dessas experiências e significados, provê condições e meios cognitivos para sua modificação por parte dos alunos e orienta-os, intencionalmente, para objetivos educativos. Está embutida aí a ajuda do professor para o desenvolvimento das competências do pensar, em função do que coloca problemas, pergunta, dialoga, ouve os alunos, ensina-os a argumentar, abre espaço para expressarem seus pensamentos, sentimentos, desejos, de modo que tragam para a aula sua realidade vivida. É nisso que consiste a ajuda pedagógica ou mediação pedagógica. (Libâneo, 1998, p. 13)

Porém, ainda é evidente que a maioria dos professores prefere ministrar aulas expositivas, onde o foco da aula não é o aluno, mas a simples transmissão do conteúdo. Apesar de ter sido escrita em 1989, a fala seguinte de D'Ambrósio pode ser considerada atual.

Sabe-se que a típica aula de matemática a nível de primeiro, segundo ou terceiro graus ainda é uma aula expositiva, em que o 
professor passa para o quadro negro aquilo que ele julgar importante. O aluno, por sua vez, copia da lousa para o seu caderno e em seguida procura fazer exercícios de aplicação, que nada mais são do que uma repetição na aplicação de um modelo de solução apresentado pelo professor. (D’AMBRÓSIO, 1989, p.15).

D'Ambrósio ainda fala que se os alunos acreditam que a aprendizagem matemática é um simples acúmulo de fórmulas e algoritmos, essa crença os faz perder a autoconfiança em suas intuições matemáticas. Em nenhum momento de uma aula de matemática, o aluno se sente motivado a solucionar um problema pela curiosidade criada pela situação em si (D'AMBRÓSIO, 1989).

Isso é corroborado por Barbosa e Moura (2013), quando dizem que:

No Brasil, convivemos com contextos educacionais tão diversificados que vão desde escolas onde os alunos ocupam grande parte de seu tempo copiando textos passados no quadro até escolas que disponibilizam para alunos e professores os recursos mais modernos da informação e comunicação. Entre esses extremos de diversidade, encontramos escolas que estão no século XIX, com professores do século XX, formando alunos para o mundo do século XXI. (BARBOSA E MOURA, 2013, p. 51)

A aprendizagem ativa tem como principais objetivos: fazer com que o aluno aprenda por intermédio da interação com o próximo; desenvolver no aluno o senso crítico e a capacidade de argumentação; acabar com o mito ainda vigente de que muitas matérias se restringem ao acúmulo de informações, principalmente para a atual "geração Z", que pode conseguir qualquer informação apenas acessando a internet; desenvolver a competência de saber trabalhar em equipe, ocasião na qual aluno só tem a ganhar, pois quando o aluno aprende a trabalhar de forma cooperativa, discutindo e expondo suas opiniões, ele se prepara melhor para o mercado de trabalho futuro, que procura pessoas que saibam trabalhar em equipes multiprofissionais. Todo método ou estratégia que promova o envolvimento e a participação ativa do aluno no processo de desenvolvimento do conhecimento contribui para formar ambientes ativos de aprendizagem.

Para Haguenauer (2005), os métodos de ensino ultrapassados podem empobrecer a criatividade e a inteligência dos jovens. Ao mesmo tempo, a autora afirma que a eficiência da aprendizagem nas universidades e na capacitação de profissionais é muito baixa quando são utilizados os métodos tradicionais. Logo, é preciso modernizar a educação para acompanhar as transformações ocorridas no mundo.

O filósofo Confúcio é autor do seguinte provérbio chinês: "O que eu ouço, eu esqueço; o que eu vejo, eu lembro; o que eu faço, eu compreendo." Silberman (1996) faz uma adaptação relacionando esse provérbio com os métodos ativos de aprendizagem: 
- O que eu ouço, eu esqueço;

- O que eu ouço e vejo, eu me lembro;

- O que eu ouço, vejo e pergunto ou discuto, eu começo a compreender;

- O que eu ouço, vejo, discuto e faço, eu aprendo desenvolvendo conhecimento e habilidade;

- O que eu ensino para alguém, eu domino com maestria.

As novas exigências educacionais e a nova sociedade da informação pedem uma nova postura do professor, "um novo professor capaz de ajustar suas didáticas às novas exigências da sociedade" (LIBÂNEO, 1998 p. 12). Como se tornar esse professor é uma indagação que muitos devem ter. Não há uma resposta única para ela, mas Libâneo aponta um caminho:

É preciso, também, uma ligação maior da formação que se realiza na faculdade com a prática das escolas, trazendo os professores em exercício para a universidade, para discussão de problemas comuns. (LIBÂNEO, 1998 p.22)

Se o professor, segundo as novas tendências deve ser mediador, é necessário que ele tenha contato com essas novas metodologias inovadoras, já durante o seu curso de graduação. 


\section{Capítulo 3}

\section{Metodologias Ativas}

Como exemplo de metodologias ativas, este capítulo irá tratar da Problem Based Learning ou Aprendizagem Baseada em Problemas (ABP), a modelagem matemática, comentando-se sobre suas vantagens e desvantagens e, por final, a Peer Instruction ou Aprendizagem pelos Colegas (ApC).

\subsection{Aprendizagem Baseada em Problemas - ABP}

A metodologia da Aprendizagem Baseada em Problemas tem sua origem no ensino de Ciências da Saúde da McMaster University, do Canadá, em 1969, sob a coordenação de Howard S. Barrows. Um pouco depois, em 1996, foi adotada na Universidade de Maastricht, Holanda (CAMP 1996). Desde então, foi aplicada em outras Universidades como Southern Illinois School of Medicine (EUA), Faculté de Medicine - Université de Sherbrooke (Canadá), Harvard Medical School (EUA) e, no Brasil, inicialmente na Faculdade de Medicina de Marília e no Curso de Medicina da Universidade Estadual de Londrina entre os anos de 1997 e 1998.

Desse modo, observa-se que, do ponto de vista histórico, a ABP está fortemente vinculada aos cursos da área da saúde, mais especificamente aos cursos de medicina.

Sakai e Lima (1996) apresentam a Aprendizagem Baseada em Problemas da seguinte forma:

O PBL é o eixo principal do aprendizado teórico do currículo de algumas escolas de Medicina, cuja filosofia pedagógica é o aprendizado centrado no aluno. É baseado no estudo de problemas propostos com a finalidade de fazer com que o aluno estude determinados conteúdos. Embora não constitua a única prática pedagógica, predomina para o aprendizado de conteúdos cognitivos e integração de disciplinas. Esta metodologia é formativa 
à medida que estimula uma atitude ativa do aluno em busca do conhecimento e não meramente informativa como é o caso da prática pedagógica tradicional. (Sakai e Lima, 1996)

Na ABP, o elemento central é o aluno, e a base é o grupo tutorial. Grupos tutoriais são grupos de 8 a 10 estudantes. Nesse grupo, o professor age como tutor. Em geral, são eleitos dois alunos, uma para coordenador e outro para secretariar as atividades do grupo. Dependendo das regras da ABP aplicada e da decisão do grupo, os cargos de coordenador e secretário devem ser submetidos a um sistema de rodízio de modo que todos os alunos tenham a oportunidade de ocupar as duas funções. A função do coordenador é conduzir a discussão de forma a controlar o tempo e encorajar a discussão de todos, enquanto a do secretário é a de registrar os pontos relevantes levantados pelo grupo, assim como as fontes de pesquisa utilizadas. Segundo Schimidt (1983), todos os alunos devem estar atentos para cumprirem os sete passos do método:

1. Leitura do problema, identificação e esclarecimento de termos desconhecidos;

2. Definição exata do problema;

3. Discussão do problema e formulação de hipóteses utilizando seus conhecimentos prévios ( "brainstorming");

4. Resumo das hipóteses formuladas no passo 3;

5. Formulação dos objetivos de aprendizagem (o grupo seleciona os objetivos nos quais vão concentrar as atividades e, se necessário, concordam em distribuir as tarefas, além de listar quais conhecimentos serão necessários auxiliar a resolução do problema);

6. Estudo Individual dos assuntos levantados nos objetivos de aprendizagem;

7. Rediscussão do problema com base nos conhecimentos adquiridos no passo 6;

Se no sétimo passo o grupo achar necessário, pode-se voltar ao passo 4 podendo, inclusive, formar um ciclo.

A aprendizagem colaborativa feita nos grupos, assim como a aprendizagem individual, resultam na construção do conhecimento na ABP.

Com base no trabalho de Schimidt, o autor Oliveira Filho (2003) aponta como principal base teórica da metodologia do AOP (Aprendizado Orientado por Problemas, outra sigla para ABP) a teoria do processamento da informação:

O AOP tem como principal base teórica a teoria de processamento de informação, segundo a qual três princípios orientam a aquisição de novas informações: (1) ativação de conhecimentos 
prévios sobre o assunto, (2) especificidade de codificação (a recuperação de informação no futuro é facilitada quando exemplos estão codificados juntamente com a informação, ou seja, quanto mais próxima a semelhança entre uma situação real e a situação de aprendizado, mais fácil a recuperação de informação), e (3) elaboração do conhecimento (através de resposta a perguntas, ensino de colegas ou verbalização do conhecimento), que cria redundância na estrutura da memória. (OLIVEIRA FILHO, 2003, P. 289)

\subsubsection{Elaboração dos Problemas}

O problema é o ponto chave para a discussão na ABP. É a essência do método. Deve levar o aluno a uma inquietação, um desequilíbrio que estimule e encoraje cada estudante a resolvê-lo. Deve, portanto, ser cuidadosamente selecionado para propiciar e estimular o aprendizado desejado.

Para elaborar os problemas, devem ser observados alguns critérios, entre os quais se incluem:

1) não deve ser muito simples nem muito complexo;

2) deve conter situações próximas da realidade dos alunos ou de sua futura área profissional;

3) deve ter um contexto próximo ao que pode ser encontrado na prática;

4) deve permitir a discussão, não se restringindo a perguntas e respostas diretas.

\subsubsection{Vantagens e desvantagens da ABP}

Naturalmente, qualquer proposta diferenciada de ação pedagógica apresenta ganhos e perdas. Barrows (1986) aponta uma série de vantagens e desvantagens da ABP. Dentre elas pode-se destacar:

- O aluno "aprende a aprender";

- O aluno produz conhecimento relevante para sua carreira futura;

- O aluno torna-se participante ativo no processo de aprendizagem proporcionando motivação;

- O aluno busca conhecimento para seu futuro profissional e não apenas por uma exigência do professor;

- O aluno adquire a capacidade de avaliar as próprias forças e fraquezas e determinar as suas necessidades de aprendizado; 
- O professor assume o papel de facilitador da aprendizagem.

- A ABP facilita a interdisciplinaridade,

Alguns autores apontam as seguintes desvantagens:

- Necessidade de produzir recursos em abundância para os alunos como livros, slides, vídeos, modelos, amostras, equipamentos etc.

- Recomendação de que a ABP não seja utilizada em disciplinas isoladas, pois iria contra à filosofia educacional da ABP que aponta para uma mudança no currículo, inclusive tornando-o mais interdisciplinar. MAMEDE(2001 p.32)

- Utilização da premissa de que a avaliação tem que ser individualizada. A conveniência de se fazer um teste para toda classe tem que ser abandonada.

- Como o aprendizado ocorre, muitas vezes, fora da sala de aula, há entre os professores e alunos, o medo de que o aluno não aprenda tudo que é considerado importante. Com isso, espera-se que haja uma série de competências que o aluno só vai conseguir após a formatura

Naturalmente, dependendo do ponto de vista, aquilo que é considerado desvantagem para alguns, pode ser considerado vantagem para outros. Por exemplo, os defensores da avaliação formativa vão apontar a necessidade de se fazer avaliação individualizada como uma vantagem, pois seria a oportunidade de se libertar das amarras impostas pela avaliação tradicional, somativa. A esse respeito, Perrenoud (1998) ensina que:

A avaliação tradicional é uma amarra importante, que impede ou atrasa todo tipo de outras mudanças. Soltá-la é, portanto, abrir a porta a outras inovações. Talvez seja exatamente isto, afinal de contas, que dá medo e que garante a perenidade de um sistema de avaliação que não muda muito, ao passo que, há décadas, vem-se denunciando suas falhas no plano docimológico e seus efeitos devastadores sobre a auto-imagem, o estresse, a tranquilidade das famílias e as relações entre professores e alunos. (...) Nenhuma inovação pedagógica maior pode ignorar o sistema de avaliação ou esperar contorná-lo. Consequentemente, é necessário em qualquer projeto de reforma, em qualquer estratégia de inovação, levar em conta o sistema e as práticas de avaliação, integrá-los à reflexão e modificá-los para permitir a mudança. (Perrenoud, 1998) 
Assim, é natural pensar que a ABP, considerada como uma inovação pedagógica exige, necessariamente, uma mudança no sistema de avaliação, devendo o professor estar aberto para isso e buscar aperfeiçoar sua prática avaliativa para contemplar esse novo cenário que se desenvolve dentro de sua sala de aula quando incorpora novas ações. Por isso, a avaliação formativa defendida por autores como Perrenoud ajusta-se melhor quando se pratica a metodologia como a ABP. Para Perrenoud

A ideia de avaliação formativa sistematiza o funcionamento, levando o professor a observar mais metodicamente os alunos, a compreender melhor seus funcionamentos, de modo a ajustar de maneira mais sistemática e individualizada suas intervenções pedagógicas e as situações didáticas que propõe, tudo isso na expectativa de otimizar as aprendizagens: "A avaliação formativa está portanto centrada essencial, direta e imediatamente sobre a gestão das aprendizagens dos alunos (pelo professor e pelos interessados)". Essa concepção se situa abertamente na perspectiva de uma regulação intencional, cuja intenção seria determinar ao mesmo tempo o caminho já percorrido por cada um e aquele que resta a percorrer com vistas a intervir para otimizar os processos de aprendizagem em curso. (Perrenoud, 1998, p.89)

Ao observar atentamente os estudantes durante uma sequência de atividades elaboradas na perspectiva da aprendizagem baseada em problemas, o professor pode exercer sua função de "regular" a aprendizagem de seus alunos, em um processo contínuo de ação-reflexão-ação.

Assim, a abordagem centrada no aluno requer maturidade e disciplina e outras habilidades mais avançadas para o professor que deverá ser: facilitador, orientador. além de avaliar o aluno como um sujeito único, responsável por sua própria educação.

\subsection{Modelagem Matemática}

A modelagem é a arte de simular situações do mundo real através de modelos matemáticos. A modelagem matemática, segundo Bassanezi, é analisar fatos da realidade e transformá-los em exemplos matemáticos, passíveis de serem estudados. Esses exemplos são chamados de modelos.

Quando se procura refletir sobre uma porção da realidade, na tentativa de explicar, de entender, ou de agir sobre ela - o processo usual é selecionar, no sistema, argumentos ou parâmetros 
considerados essenciais e formalizá-los através de um sistema artificial: o modelo. [...] A Modelagem Matemática consiste na arte de transformar problemas da realidade em problemas matemáticos e resolvê-los interpretando suas soluções na linguagem do mundo real. (Bassanezi, 2002, p. 19)

Já Skovsmose (2001) diz que a Modelagem Matemática é um ambiente de aprendizagem "[...] em que alunos são convidados a investigar situações com referência na realidade". Para Biembengut e Hein "um conjunto de símbolos e relações matemáticas que procura traduzir, de alguma forma, um fenômeno em questão ou problema de situação real, denomina-se modelo matemático".

Em um levantamento bibliográfico nacional e internacional sobre pesquisas com modelagem, Bean (2001, p.56) diz que a falta de clareza sobre o conceito "reside em parte, na complexidade de transferir ou adaptar a atividade do modelador (matemático, engenheiro, biólogo, etc.) ao campo de ensino onde atua o professor de matemática".

Mesmo não havendo um consenso em relação ao conceito de Modelagem Matemática é possível identificar em cada uma delas que a problematização e a resolução de problemas fazem parte da essência das atividades. Além disso, essa falta de consenso revela a grande amplitude do uso da modelagem matemática, onde cada professor deve escolher um tema condizente com a realidade de seus alunos.

Segundo Biembengut (2009), o termo Modelagem Matemática já era citado como um processo para descrever, formular modelar e resolver uma situação problema já no início do século XX em áreas como engenharia e ciências econômicas.

Já no final dos anos 1970 e início dos anos 1980, algumas pessoas foram de grande importância para a disseminação do uso da modelagem matemática no Brasil como Aristides C. Barreto, Ubiratan D’Ambrosio, Rodney C. Bassanezi, João Frederico Mayer, Marineuza Gazzetta e Eduardo Sebastiani.

A Modelagem Matemática tem ocupado um papel mais presente no meio das metodologias ativas voltadas para a matemática no Brasil, uma vez que outras metodologias como a Aprendizagem Baseada em Problemas(ABP) e a Aprendizagem Baseada em Projetos (ABProj) não tiveram a mesma repercussão.

\subsubsection{Etapas da Modelagem Matemática}

Segundo Bassanezi(2002 pp.27-31), são cinco as etapas da Modelagem Matemática:

1. Experimentação:

Nesta fase se faz a obtenção dos dados e o estudo inicial do assunto que envolve o problema.

2. Abstração: 
Esta fase tem como objetivo a criação dos modelos matemáticos. Nesse sentido, é feita a seleção de variáveis, isto é, definir claramente quais são as variáveis que vão agir sobre o sistema, bem como dando ênfase na criação dos problemas teóricos que se pretende resolver, formulando hipóteses.

Em um próximo passo é feita a eliminação de variáveis menos importantes, de forma a deixar o problema matemático tratável, chamado de simplificação. Os fenômenos tratados na matemática geralmente são muito complexos quando considerados todos os seus detalhes.

3. Resolução:

Obtenção do modelo matemático com a tradução da linguagem natural das hipóteses para uma linguagem matemática coerente, mais "natural".

4. Validação:

Aceitação ou rejeição do modelo de acordo com o grau de aproximação com o objeto de estudo. É analisado se o modelo proposto serve para resolver o problema e fazer previsões de novas situações.

5. Modificação:

Reelaboração ou reformulação do modelo, caso este não tenha sido validado na etapa anterior.

Criação de novas hipóteses, caso necessário, o que implicará numa reformulação do modelo.

\subsubsection{Vantagens da Modelagem Matemática}

A modelagem pressupõe multidisciplinaridade. Assim, Bassanezi (2002) aponta como vantagens da modelagem, a remoção de fronteira entre as áreas de pesquisa e a observação de alternativas no direcionamento de suas aptidões ou formação acadêmica por parte do aluno.

A Modelagem Matemática como estratégia de ação provoca o aluno a pensar, analisar, criar e estabelecer relações, defender argumentos, tomar decisões, permitindo a ele analisar o mundo em que vive. O aluno gera seu próprio conhecimento através da situação-problema envolvida na modelagem.

\subsubsection{Desvantagens da Modelagem Matemática}

Como uma possível desvantagem alguns professores podem afirmar que a Modelagem pode gastar um grande tempo precioso e que não seria possível cumprir todo conteúdo programático previsto. Nesse ponto, Irene de Albuquerque em sua obra Metodologia da Matemática afirmava que 
proporcionar à criança o prazer da "redescoberta" é um direito que lhe tem sido negado em detrimento do êxito do próprio ensino. Quando ela é capaz de descobrir uma regra e chegar a enuncia-la, essa regra está sabida para sempre, e o tempo gasto são alguns minutos. Se, ao contrário, na ânsia de economizar tempo e esforço, damos a regra, o "saber pronto" para a criança usar, estamos oferecendo uma tarefa muito mais difícil e desinteressante, e a sua aprendizagem vai tomar-nos vários dias; voltaremos a insistir no mesmo assunto daí a semanas, daí a meses, porque haverá sempre o "esquecimento"; o que nós nunca confessamos a nós mesmos é que a criança esquece justamente porque nunca chegou a aprender. (ALBUQUERQUE, 1951 p. 7)

\subsection{Aprendizagem pelos Colegas}

A aprendizagem pelos colegas (em inglês, Peer Instruction) é uma técnica que tem como objetivo envolver os alunos promovendo a discussão entre eles de tópicos propostos pelo professor. Nela, os alunos estudam a parte teórica em casa e em sala discutem entre si a respeito de questões que envolvem o assunto estudado. Atende bem aos Parâmetros Curriculares Nacionais:

O ensino de Matemática prestará sua contribuição à medida que forem exploradas metodologias que priorizem a criação de estratégias, a comprovação, a justificativa, a argumentação, o espírito crítico, e favoreçam a criatividade, o trabalho coletivo, a iniciativa pessoal e a autonomia advinda do desenvolvimento da confiança na própria capacidade de conhecer e enfrentar desafios.

É importante destacar que a Matemática deverá ser vista pelo aluno como um conhecimento que pode favorecer o desenvolvimento do seu raciocínio, de sua capacidade expressiva, de sua sensibilidade estética e de sua imaginação. (PCN, 1997, p. 26)

Trabalhar coletivamente, por sua vez, supõe uma série de aprendizagens, como:

- perceber que além de buscar a solução para uma situação proposta devem cooperar para resolvê-la e chegar a um consenso;

- saber explicitar o próprio pensamento e tentar compreender o pensamento do outro;

- discutir as dúvidas, assumir que as soluções dos outros fazem sentido e persistir na tentativa de construir suas próprias idéias; 
- incorporar soluções alternativas, reestruturar e ampliar a compreensão acerca dos conceitos envolvidos nas situações e, desse modo, aprender.

A Peer Instruction ou, em uma tradução livre, Aprendizagem pelos Colegas, surgiu em 1990 quando o professor Eric Mazur da Universidade de Havard se deparou com uma série de artigos de Halloun e Hestenes sobre o mal aproveitamento da aprendizagem de alunos de graduação nas matérias de física. Os pesquisadores, Ibrahim Abou Halloun e David Hestenes, investigaram o aprendizado de alunos de física de universidades, com o pressuposto que todos eles já possuíam um sistema de crenças e intuições sobre os fenômenos físicos. Essas crenças advinham das próprias experiências pessoais dos alunos. Para avaliar esses conceitos, eles criaram um teste chamado de Force Concept Inventory (FCI) que, "sendo composto por 29 questões, cada uma com 5 alternativas de respostas. Uma alternativa correspondente ao conceito cientificamente aceito e as demais a um conceito intuitivo previamente estabelecido." (FERNANDES e TALIM, 2009). Eles constataram que o aprendizado era ineficiente para mudar essas crenças, mesmo sendo este um dos objetivos das disciplinas introdutórias de física.

Até então o professor Mazur 11 ensinava de forma convencional, com aulas sempre expositivas, e sempre obtivera resultados muito bons nas provas de seus alunos.

Intrigado com a pesquisa, o professor Mazur decidiu aplicar o teste feito pelos pesquisadores Halloun e Hestenes e verificou que realmente seus alunos não conseguiam compreender os fenômenos físicos corretamente.

De primeira vista, a diferença entre o teste FCI e as provas que o professor Mazur costumava aplicar era que no teste dos referidos pesquisadores as questões eram contextualizadas e relacionadas com o cotidiano.

Ele conta que, de imediato, pôde compreender que os alunos conseguiam fazer as difíceis questões dos livros e das provas, mas não conseguiam resolver um problema relativamente fácil do cotidiano. Os alunos memorizavam, mas não compreendiam.

Foi durante uma aula de revisão de uma dessas provas que o professor Mazur teve uma inesperada ideia. Após duas tentativas sem sucesso de explicar uma questão que ele julgava fácil, Mazur falou para os alunos discutirem suas respostas com o colega ao lado. Ele sabia que cerca de metade dos alunos tinham acertado essa questão. A aula se tornou um caos, porém, após alguns instantes, evidenciou-se que os alunos tinham realmente entendido a questão.

Mazur começou a entender que algumas vezes é mais fácil o aluno entender a linguagem do colega e interagir com ele, do que fazer o mesmo com o professor. Ele

\footnotetext{
1 Algumas partes da história foram contadas pelo prof. Eric Mazur em um vídeo de título "Instruções pelos pares na aprendizagem ativa (legendado)", encontrado no endereço eletrônico: $<$ https://www.youtube.com/watch?v=iCDXyIrYNS8>. Acesso em: 19 jul. 2016.
} 
aceitou como justificativa que o professor muitas vezes se esquece de como um assunto, a primeiro momento, pode ser complicado. Por outro lado, o aluno que acabou de aprender está familiarizado com as dificuldades desse assunto.

Segundo Piaget, a criança socializa mais quando está entre os alunos de mesma idade:

Eis porque a criança se socializa mais, ou de modo diferente, com os seus semelhantes do que com os adultos. Onde a superioridade do adulto impede a discussão e a cooperação, o companheiro dá ocasião a essas condutas sociais, que determinam a verdadeira socialização da inteligência. De maneira oposta, onde a igualdade dos companheiros impede a questão ou a interrogação, o adulto está a sua disposição para responder. (PIAGET, 1959, pp. 94-95).

Naturalmente, quebrar paradigmas e mudar práticas já cristalizadas nas quais acreditamos serem eficazes, não é algo tão fácil. Além disso, a lei da inércia é algo bastante forte: é muito mais cômodo continuarmos a fazer as coisas sempre do mesmo jeito, seguindo "a onda". Mas, então, como aplicar a Peer Instruction?

Para a Peer Instruction ser bem-sucedida, é necessário que o livro e as aulas expositivas desempenhem papéis diferentes dos que costumam exercer em uma disciplina convencional. (MAZUR, 2015, p. 10)

Antes da aula, o aluno faz uma leitura das partes conceituais contidas no livro. A seguir, nas aulas expositivas, o professor esclarece as dificuldades principais, aprofunda a compreensão, cria confiança e fornece exemplos adicionais. O livro serve de referência e guia de estudo.

Em uma aula anterior à aula prevista, o professor deve entregar um material complementar para leitura em casa ou selecionar trechos importantes do livro didático.

Para que a aprendizagem pelos colegas seja mais bem aproveitada, é necessário ao educador elaborar um banco de questões separadas por dificuldade sobre cada assunto. Essas questões serão utilizadas mais tarde nos testes conceituais e nas discussões em sala de aula.

A aprendizagem pelos colegas tem como objetivos principais explorar a interação entre os estudantes e aumentar o foco nos conceitos fundamentais. As longas aulas em que o professor apresenta detalhadamente todo o material são substituídas por apresentações curtas sobre os pontos-chaves seguidos de um teste conceitual.

Ao iniciar a aula, o professor fará uma breve exposição sobre o conteúdo planejado, considerando que todos leram o material teórico ou o livro antes da aula. 
Após essa explicação, o professor aplica o teste conceitual. Esse teste possui pequenas questões conceituais abrangendo o assunto.

Os alunos possuem um breve momento para responder, que pode ser de cerca de dois minutos, por exemplo. Após isso, os alunos informam suas respostas individuais por intermédio de gestos com as mãos, placas com as alternativas A, B, C, D ou E, ou por meio de clickers.

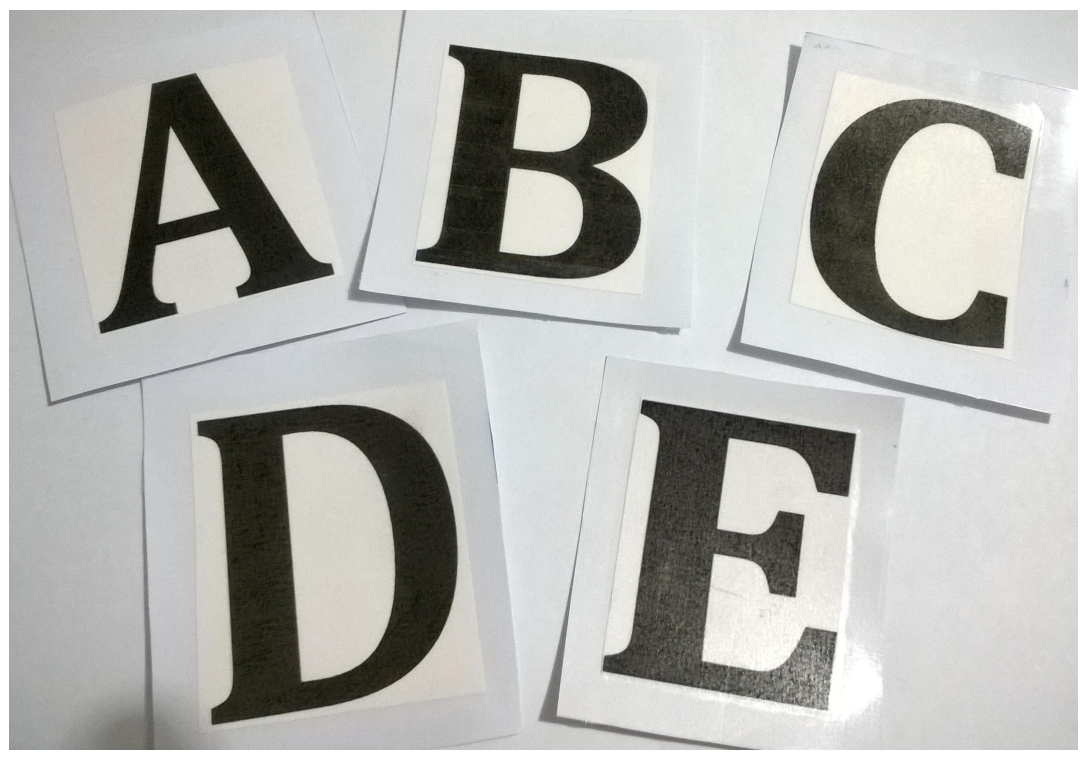

Figura 3.1: exemplo de Flashcards Fonte: elaboração do autor

Os flashcards ilustrados figura 3.1 podem ser feitos de vários materiais como plástico, cartolina com papel contact, entre outros. O tamanho varia e deve ser o suficiente para o professor enxergar as respostas de todos os alunos de qualquer lugar do ambiente de aula.

Os Clickers são dispositivos eletrônicos que se comunicam por radiofrequência com um receptor que conectado com o computador do professor, mostra a contagem e porcentagem de todas as respostas dos alunos.

Outros dispositivos como tablets, notebooks ou até aplicativos instaláveis em smartphones também podem ser usados para o envio das respostas de questões objetivas ou até mesmo de questões discursivas.

O funcionamento da aprendizagem pelos colegas pode ser resumido no seguinte diagrama:(ARAUJO, MAZUR, 2013 p.)

Se, após o envio das respostas, a porcentagem de acerto foi muito baixa (abaixo de 30\%), o professor ensina novamente o tópico mais lentamente e com mais detalhes e propõe uma nova questão. 


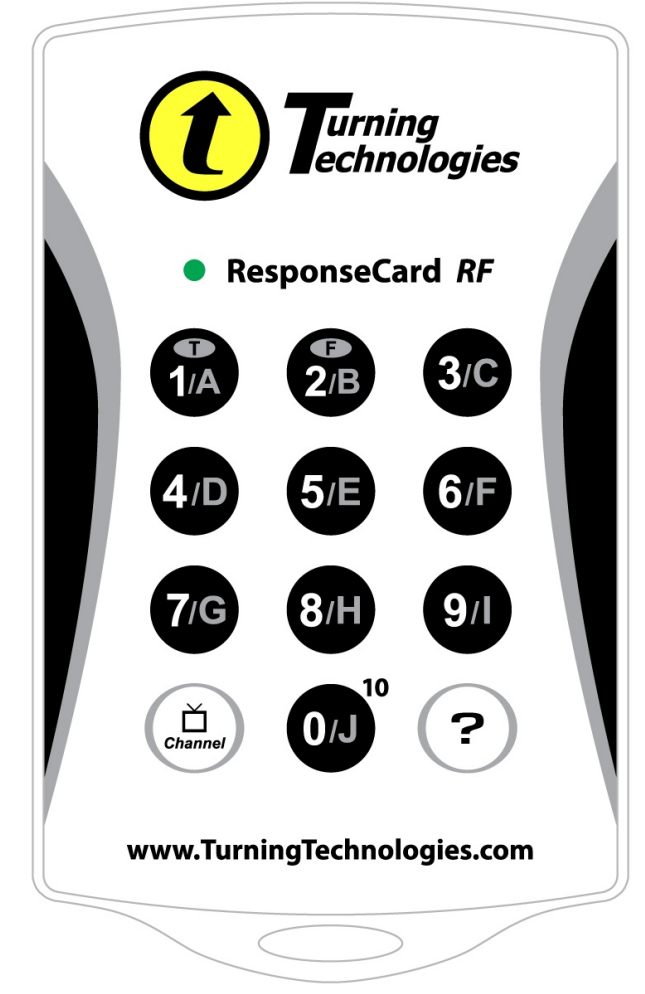

Figura 3.2: exemplo de um clicker

Fonte:

$<$ http://turningtechnologies.com.br/images/images/products/student/ResponseCard_RF_Vector.jpg $>$

A avaliação, no caso, seria um mecanismo subsidiário pelo qual o professor iria detectando os níveis de aprendizagem atingidos pelos alunos e trabalhando para que atingissem a qualidade ideal mínima necessária. Só passaria para um conteúdo novo, quando os alunos tivessem atingido esse patamar mínimo. (LUCKESI, 1998, pp. 71-80)

Se a porcentagem está acima de 70\%, o professor pode explicar o resultado e rapidamente passar para outra questão ou para o próximo tópico.

Se a porcentagem de acerto estiver entre $30 \%$ e $70 \%$, o professor propõe aos alunos que discutam com outro colega sobre sua resposta, observando algumas dessas discussões. Após isso, será feita uma segunda aferição dos resultados. Se forem bons, um novo tópico pode ser iniciado. Porém, se não houver melhora significativa, o professor pode explanar sobre a questão e propor outra questão ainda sobre o mesmo assunto, caso ache necessário.

Uma grande vantagem da aprendizagem pelos colegas é que o feedback é imediato. O professor sabe a cada resposta mostrada pelos alunos, qual a porcentagem de alunos que provavelmente entendeu o conceito, pois acertaram uma questão proposta. 


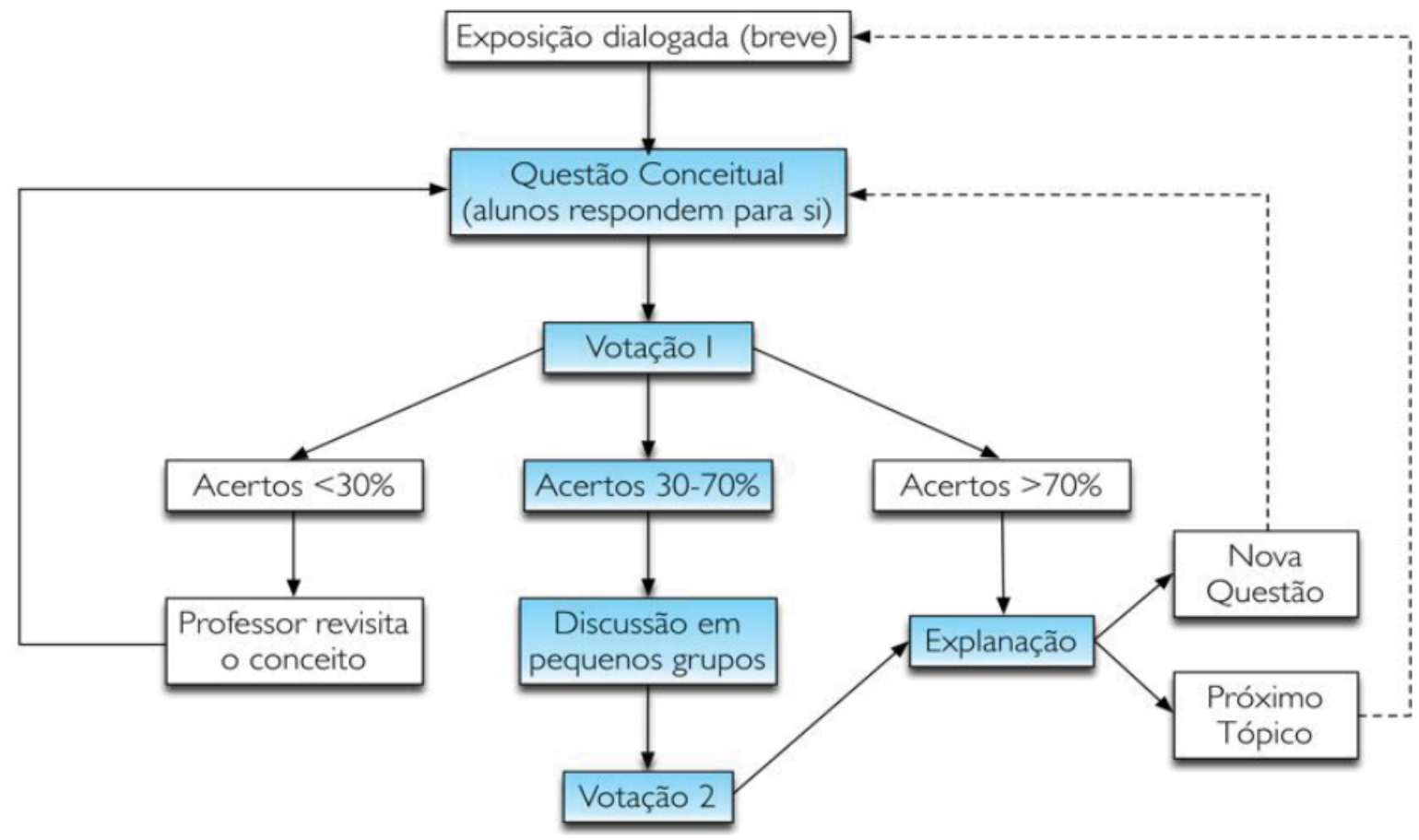

Figura 3.3: Diagrama de funcionamento da aprendizagem pelos colegas. Em destaque está a parte crucial do método, a interação entre os alunos.

Um dos pontos fundamentais dessa metodologia é a escolha adequada das questões que serão aplicadas em cada tópico. Para isso, o professor precisa ter um bom banco de questões, do qual poderá extrair de acordo com o contexto de cada turma, já que nem sempre o que funciona bem com um grupo de estudantes vai se comportar da mesma forma com outro.

Como escolher as questões para aplicar em cada tópico:

As questões ideais são as que alcançam entre $40 \%$ a $80 \%$ de acerto. Questões fora dessa faixa são consideradas questões muito fáceis ou muito difíceis. Assim, para garantir que sempre seja possível a discussão entre pares só serão mantidas questões que com frequência atinjam essas porcentagens de acerto.

Questões mais desafiadoras são apoiadas por Luckesi:

o conteúdo novo proposto para a aprendizagem deve ser mais avançado que o estágio em que o educando se encontra, porém não tão novo de forma que o educando não tenha como assimilálo. (LUCKESI, 2002, p.134).

Um dos objetivos da ApC é proporcionar um espaço de discussão entre os alunos, o que poderia ser feito também com um trabalho em grupo, mas a ApC é mais efetiva por ser feita durante a aula, gastando menos tempo e impedindo que os alunos dividam as tarefas ou que as tarefas fiquem concentradas em alguns alunos do grupo. 
O planejamento de uma aula com aprendizagem pelos colegas, principalmente com a elaboração das questões conceituais, será vista mais à frente no capítulo de aplicação junto com a proposta de aula de função afim.

\subsection{Just-in-Time-Teaching - Ensino sob Medida (EsM)}

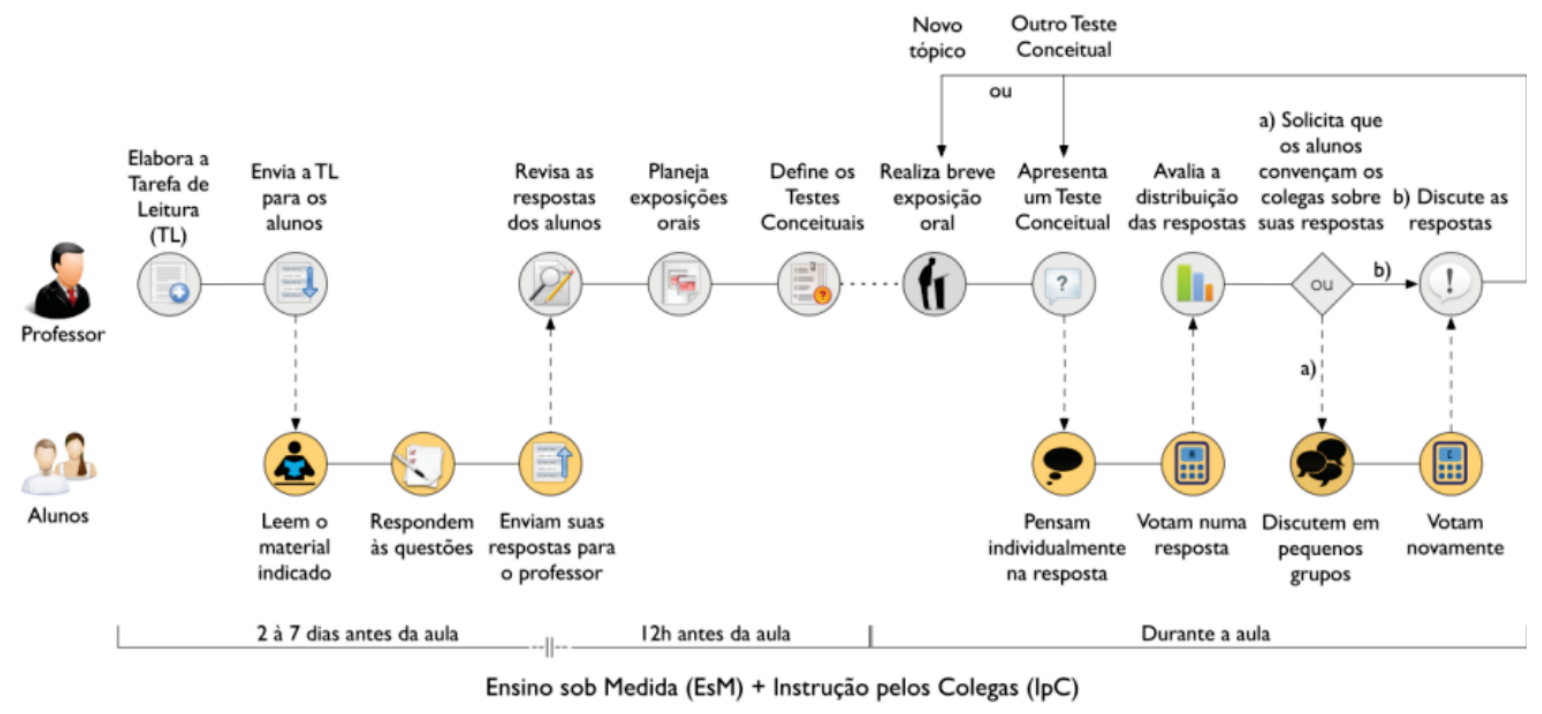

Figura 3.4: Linha do tempo das metodologias aprendizagem pelos colegas e ensino sob medida.

Fonte: MAZUR, E; WATKINS, J. Just-in-Time Teaching and Peer Instruction. In: SIMKINS, S.; MAIER, M. (Eds.). Just-In-Time Teaching: Across the Disciplines, Across the Academy Just-In-Time Teaching. 1. ed. Sterling: Stylus Publishing, 2010. p. 39-62.

O ensino sob medida (Just-In-Time-Teaching) surgiu em 1996 por Gregory M. Novak. Nele o professor indica ou forneçe um material para que os alunos estudem antes da aula. Esse material pode ser uma parte do livro-texto, uma referência na internet, ou um material feito pelo próprio docente. O EsM não se resume a apenas a leitura prévia dos conteúdos em casa. O aluno deve responder um questionário com questões conceituais e com nível de dificuldade adequado para que o ele consiga pensar a respeito. Esse questionário, chamado de "exercício de aquecimento" (WarmUp exercise), deve ser respondido um certo tempo antes da aula por meio eletrônico, geralmente 24 horas antes da aula. De posse das respostas dos alunos o professor prepara a aula focando nos tópicos com maior dificuldade dos alunos, deixando de lado conceitos que os alunos já entenderam, otimizando o tempo de aula.

As perguntas podem ser do tipo:

- Você achou os textos confusos?

- Qual parte você achou confuso? 
- Qual/quais partes você achou interessante(s)?

A ideia é que o professor analise antes da aula as respostas dos alunos nas tarefas de leitura e prepare a sua aula de modo a atender essas principais dificuldades e não perder tempo explicando aquilo que os alunos possam aprender com uma simples leitura do texto.

Pode-se definir uma pontuação para que o aluno se sinta motivado a estudar o conteúdo antes da aula.

Segundo a literatura, constituem vantagens do EsM:

- Aumentar o aprendizado em sala de aula

- Aumentar a motivação pelo assunto ensinado

- Encorajar os alunos a se prepararem para a aula

- Permitir ao professor ajustar as atividades em classe para melhor atendes às necessidades dos alunos

No que diz respeito às desvantagens do método, aponta-se que as tarefas online exigem que todos os alunos tenham acesso à internet, pois parte do conteúdo é passado pela internet, o alto custo de implantação com datashows, administração de plataforma online, entre outras.

Tomando o conjunto completo dos métodos descritos acima em conta, o ciclo de seis passos de uma única reunião de sala de aula com EsM é:

1. Estudantes completam a leitura ou os outros trabalhos preparatórios;

2. Estudantes fazem o teste de leitura;

3. Um membro do corpo docente comenta as tarefas de leitura, e considera mudanças na ênfase da aula;

4. Um membro da faculdade seleciona citações das tarefas de leitura para se referir durante a aula;

5. Durante a aula, um membro do corpo docente usa citações de trabalhos dos alunos para liderar a discussão do material;

6. Durante a aula, os alunos se envolvem na discussão do material com o membro do corpo docente e um com o outro.

O membro do corpo docente cria ou ajusta próxima tarefa pré-classe para melhor atender às necessidades dos estudantes em função dos progressos realizados durante as aulas. 


\subsection{EsM em conjunto com ApC}

Apesar do EsM não ser uma metodologia tão centrada nos alunos como as outras vistas até agora, ela pode ser perfeitamente usada junto com a ApC. Escolher questões ideais antes da aula é uma das principais dificuldades do método da ApC e, por meio da análise das tarefas de leitura, o professor, conhecendo as principais dificuldades e interesses, pode elaborar questões que vão de encontro com as dúvidas dos alunos.

Pesquisando apenas por um termo ou outro nas principais páginas de busca na internet com frequência se encontram páginas em língua portuguesa que falem das duas metodologias usadas em conjunto. O professor Eric Mazur recomenda o uso do Ensino sob Medida junto da ApC:

Para assegurar que façam suas tarefas de leitura antes da aula implementei o Just-in-Time-Teaching, uma técnica muito efetiva que complementa a Peer Instruction (...). Antes de implementar o Just-in-Time-Teaching, eu aplicava de três a quatro testes de leitura no começo de cada aula. (...) Embora eu recomende fortemente o uso de Just-in-Time-Teaching no lugar dos testes de leitura, eu incluí neste livro uma coleção completa de testes e leitura (MAZUR, 2015, p. 24)

O professor Mazur indica o uso do EsM nos casos em que há o amparato tecnológico disponível para o professor. Caso contrário pode ser utilizado os testes de leitura propostos pela ApC. 


\section{Capítulo 4}

\section{Proposta de uma aula sobre função afim com o uso da Aprendizagem pelos Colegas}

Aplicada inicialmente em aulas de exercícios e estimulando o estudo prévio dos alunos, a ApC pode facilitar a inserção de metodologias ativas por professores que estejam acostumados a ministrar somente aulas tradicionais, expositivas.

\subsection{Preparação do material teórico}

O material teórico pode ser de vários tipos:

- material impresso;

- páginas de internet;

- trecho ou capítulo do livro didático;

- vídeos na internet ou obtidos de outras fontes.

Tendo como finalidade a aplicação do método em salas de aula de uma escola pública do DF, foi escolhido confeccionar um material que pudesse ser impresso em poucas folhas para serem entregues aos alunos uma aula antes da aplicação do método. É usual os alunos criarem certa resistência em ler os materiais antes da aula, principalmente se for em sítios de internet, pois nem todos podem ter acesso fácil a web, uma realidade ainda presente nas escolas públicas.

Para produzir um material teórico sobre função afim, partiu-se da noção de proporcionalidade, conforme exposto nos PCN: 
A proporcionalidade, por exemplo, que já vem sendo trabalhada nos ciclos anteriores, aparece na resolução de problemas multiplicativos, nos estudos de porcentagem, de semelhança de figuras, na matemática financeira, na análise de tabelas, gráficos e funções. [...] O aluno poderá desenvolver essa noção ao analisar a natureza da interdependência de duas grandezas em situações-problema em que elas sejam diretamente proporcionais, inversamente proporcionais ou não proporcionais (função afim ou quadrática). Essas situações são oportunas para que se expresse a variação por meio de uma sentença algébrica, representando-a no plano cartesiano. (BRASIL, 1998, pp. 84-85).

O material teórico contém um exemplo de preparo de uma limonada suíça que foi utilizado para ilustrar o conteúdo de proporcionalidade. Em um segundo exemplo, ainda falando sobre proporções, se introduz uma fórmula que relaciona o lucro com vendas de um vendedor com a quantidade de produtos vendidos, mas ainda sem ter um valor inicial. Em seguida, é apresentada uma situação que envolve o conceito de valor inicial. Por último, há um exemplo de situação na qual a taxa de variação é negativa. Todos os exemplos buscam contextos mais próximos do dia a dia do aluno, tendo como objetivo que o aluno possa relacionar situações de sua realidade com funções afins, somente pela identificação de valor inicial e da taxa de variação.

A leitura do material teórico em casa tem como objetivos:

- introduzir o conteúdo, ou seja, transmitir a informação aos alunos por meio de uma leitura que será feita em casa;

- tornar a aula menos "carregada" de conteúdo teórico;

- focar a aula no entendimento do conceito e não somente na sua transmissão;

- passar para o aluno a ideia de que ele também é responsável pela sua aprendizagem;

- estimular o aluno a ter uma atitude mais ativa em relação à aprendizagem de matemática, tanto em casa quanto durante a aula.

\subsection{Confecção dos Flashcards}

Para a aplicação da ApC, o uso de algum meio de captação das respostas é obrigatório. Para esta proposta foi escolhido o uso dos flashcards. As letras foram impressas em papel canson, coladas em cartolina, revestidas de papel contact para evitar que os cartões sujem com o manuseio constante, e, por último, foi feito o recorte. 


\subsection{Teste de Leitura}

Os objetivos do Teste de Leitura contemplam: verificar o empenho do aluno em ler as tarefas em casa e mostrar ao aluno que o professor vai, de fato, avaliar se ele leu o material teórico. Isso é necessário pois os estudantes costumam perceber que se algo não está sendo avaliado, então não precisa ser feito. Inicialmente, os testes de leitura podem até valer alguma pontuação extra para estimular os alunos, mas com o uso contínuo do método, os alunos perceberão a importância de estudar antes da aula e se empenharão mais. Não se trata de avaliar ainda se eles interpretaram adequadamente os conceitos envolvidos no texto, mas tão-somente verificar se a leitura foi feita, por isso essas questões devem ser simples, de resposta imediata.

Abaixo, estão três questões como exemplo de teste de leitura, baseado na leitura do material teórico de função afim:

1) O texto explorou exemplos que envolvem
A) frações.
B) volume.
C) porcentagens.
D) trigonometria.
E) proporcionalidade.

2) A receita presente no texto era de um(a)
A) bolo.
B) caipirinha.
C) carne assada.
D) limonada suíça.
E) empadão goiano.

3) No texto, a profissão de Juberval era
A) advogado.
B) cozinheiro.
C) professor.
D) vendedor de sapatos.
E) vendedor de raspadinha.

Fazendo um paralelo com a metodologia Ensino sob Medida, caso esta fosse utilizada, o teste de leitura seria feito pela internet com o uso de computador, tablet ou celular. Haveria uma obrigatoriedade de entrega antes da aula (cerca de 24 horas antes) e seriam inseridas mais uma ou duas perguntas do tipo: Em que parte do texto 
você sentiu mais dificuldade? Quais assuntos te interessaram mais? Dessa forma, o professor planejaria a aula e as questões conceituais conforme as dificuldades elencadas pelos alunos.

\subsection{Elaboração das questões conceituais:}

Segundo Mazur (2015, p. 28), cada questão conceitual deve focar um único conceito, conter respostas adequadas de múltipla escolha, não depender de equações decoradas para serem resolvidas e não podem ser nem fáceis nem difíceis demais.

Cada um desses critérios afeta a eficiência do método. Segundo Mazur (2015), se uma questão envolver muitos conceitos, o professor não saberá onde está a dificuldade da turma. Se não contemplar respostas de múltipla escolha, a votação com feedback rápido não poderá ser feita. Se depender de simplesmente jogar valores em uma fórmula, o entendimento do conceito não estará sendo avaliado e, por fim, se forem fáceis (acerto maior que 70\%) ou difíceis demais (acerto menor que 30\%) não poderá ser feita a interação entre os pares, pois a essência do método é que haja essa discussão entre os alunos.

O ideal é aparecer nas alternativas erradas as respostas mais comuns de alunos que não sabem o devido conceito. Isso é chamado também de distrator. Distrator é a alternativa que não é a correta. O distrator deve fazer parte do conceito do item e deve ser uma resposta possível para um aluno que não sabe ou não entendeu a competência que está sendo avaliada nessa questão. (Rabelo, 2013, p.191). No processo de elaboração dessas questões, foram observadas as recomendações referentes à metodologia de construções de itens descritas por Rabelo (2013).

As questões conceituais aplicadas nessa atividade estão descritas a seguir. As três primeiras avaliam se os alunos entendem o conceito de imagem.

1) Na função afim $g: R \rightarrow R \operatorname{com} g(x)=-2 x+6$, o valor da imagem de $x=3$ pode ser calculado substituindo-se da seguinte forma:
A) $g(3)=-23+6$
B) $g(3)=-3+6$
C) $g(3)=-2.3$
D) $g(3)=-2.3+6$
E) $g(3)=-2+3+6$

2) Na função afim $f: R \rightarrow R \operatorname{com} f(x)=x+8$, o valor da imagem de $x=5$ é expresso pelo termo

A) $f(5)=5$. 

B) $f(5)=10$.
C) $f(5)=13$.
D) $f(5)=16$.
E) $f(5)=40$.

3) Na função afim $f: R \rightarrow R \operatorname{com} f(x)=x+8$, o valor de " $x$ " que tem como imagem o $f(x)=30$ é
A) $x=38$.
B) $x=32$.
C) $x=28$.
D) $x=22$.
E) $x=20$.

4) Josenildo possui um plano de telefone que possui uma assinatura mensal de $\mathrm{R} \$ 20,00$, mais uma cobrança de $\mathrm{R} \$ 0,20$ por cada minuto utilizado. Para que sua conta não ultrapasse o valor de $\mathrm{R} \$ 60,00$, ele poderá falar, em cada mês, no máximo por até
A) 150 minutos.
B) 160 minutos.
C) 180 minutos.
D) 200 minutos.
E) 220 minutos.

5) Na empresa Freeway onde o valor do pacote de viagens ("p") depende da quantidade ("x") de pessoas que assinarão o contrato e pode ser representado pela fórmula: $p(x)=8000-10 x$. O valor do pacote por pessoa, caso o contrato seja fechado com 30 pessoas, será de
A) $\mathrm{R} \$ 8.300,00$.
B) $\mathrm{R} \$ 7.970,00$.
C) $\mathrm{R} \$ 7.800,00$.
D) $\mathrm{R} \$ 7.700,00$.
E) $\mathrm{R} \$ 5.000,00$.

6) Na empresa de viagens Freeway, o gerente decidiu definir um valor mínimo de lucro de $\mathrm{R} \$ 1.000,00$ por pacote vendido. Assim, supondo-se que a empresa possui um gasto total por pacote de $\mathrm{R} \$ 5.000,00$ (passagem aérea, hospedagem, alimentação e outros serviços), cada pacote pode ser vendido pelo valor mínimo de
A) $\mathrm{R} \$ 5.000,00$
B) $\mathrm{R} \$ 6.000,00$ 

C) $\mathrm{R} \$ 7.000,00$
D) $\mathrm{R} \$ 8.000,00$
E) $\mathrm{R} \$ 9.000,00$

Outro objetivo da questão 6 é dar suporte para a resolução da questão 7, a seguir.

7) Na empresa Freeway, lembrando que o preço do pacote é definido pela fórmula $p(x)=8000-10 x$, e mantendo o lucro de $\mathrm{R} \$ 1.000,00$, a empresa pode fechar o contrato para no máximo
A) 100 pessoas.
B) 200 pessoas.
C) 300 pessoas.
D) 400 pessoas.
E) 500 pessoas.

8) Juberval tem o seu salário definido pela fórmula: $s(x)=10 x+700$, onde "x" é a quantidade de sapatos vendidos e 700 é o seu salário base mensal, que ele recebe independentemente da quantidade de sapatos vendidos. Para obter um salário de exatamente $\mathrm{R} \$ 1.500,00$, Juberval deve vender
A) 8 sapatos.
B) 50 sapatos.
C) 70 sapatos.
D) 80 sapatos.
E) 150 sapatos.

9) Observe o esquema de montagem a seguir:
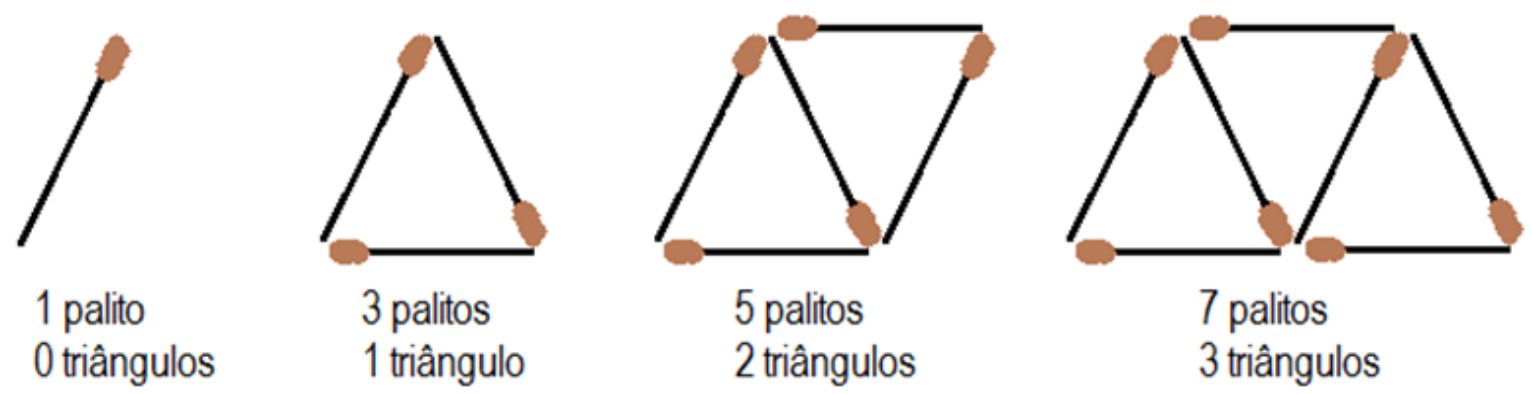

Figura 4.1: Esquema de montagem com palitos.

Fonte: elaboração do autor

Seguindo esse esquema, para montar 47 triângulos, serão necessários exatamente 

A) 141 palitos.
B) 125 palitos.
C) 115 palitos.
D) 100 palitos.
E) 95 palitos.

10) Observando o esquema de montagem da questão dos triângulos e utilizando apenas 95 palitos, será possível fazer exatamente
A) 31 triângulos.
B) 35 triângulos.
C) 39 triângulos.
D) 43 triângulos.
E) 47 triângulos.

Em relação às questões 9 e 10, pode ser utilizada uma ou outra, pois uma questiona a quantidade de palitos e a outra questiona a quantidade de triângulos formados, dependendo do entendimento da turma.

11) Carlito tem uma conta corrente com 90 reais de saldo, porém ele não está movimentando a conta. A cada final de mês, é debitada uma quantia de 15 reais referente ao seu pacote de serviços bancários. Ele irá ficar com saldo negativo na sua conta exatamente após
A) 7 meses.
B) 6 meses.
C) 5 meses.
D) 4 meses.
E) 3 meses.

Este problema visa colocar os alunos a trabalharem com taxa de decrescimento e obterem o zero da função.

12) Em uma grande pizzaria de Brasília, Júlio quer fazer o seu aniversário. Para isso, todos irão se sentar juntando as mesas como na figura 4.2:

Para que todas as 120 pessoas possam se sentar, elas deverão juntar
A) 30 mesas.
B) 40 mesas.
C) 49 mesas.
D) 55 mesas. 


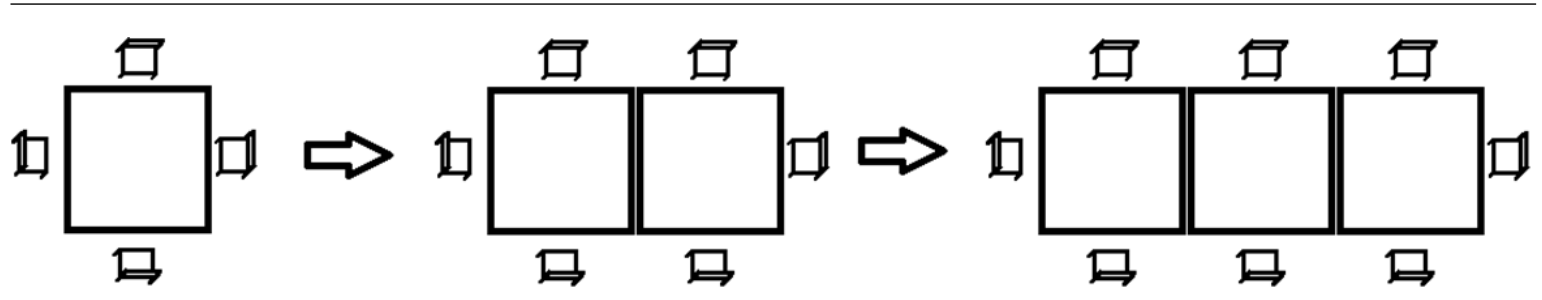

Figura 4.2: Exemplo de mesas sendo juntadas em um restaurante.

Fonte: elaboração do autor

E) 59 mesas.

Esse problema pode ter a solução baseada na questão dos palitos, mesmo parecendo ser uma questão de progressão aritmética. Porém, nesse caso acima, foi pensado em usar um exemplo: $\mathrm{x}=$ quantidade de mesas, $\mathrm{y}=$ quantidade de pessoas que poderão sentar nelas.

O objetivo dessa questão é que os alunos observem que o valor inicial não é igual a b, pois o valor inicial é 4 para $\mathrm{x}=1$ mesa. Para montar a equação, deve-se obter o valor de $y$ para $x=0$, ou subtrair o valor da taxa de crescimento $y(0)=4-2=2=b$. Dessa forma, a equação se reduzirá a: $y(x)=2 x+2$ Substituindo $y=120$, tem-se $x=59$ mesas

Durante a elaboração das questões foi observado que essa etapa demandava uma grande quantidade de tempo por parte do professor, além da dificuldade de se elaborar questões que avaliem somente um conteúdo, de se elaborar questões divididas por níveis para serem usadas em sala de aula e o uso de material tecnológico como datashows e clickers, que podem não estar disponíveis em todas as escolas. 


\section{Capítulo 5}

\section{Aplicação da ApC em sala de aula}

Para a aplicação da ApC em sala de aula, foram confeccionados 35 kits de flashcards, cada kit com as letras A, B, C, D e E, impressas em papel canson, colados em cartolina e cobertos com papel contact para aumentar a durabilidade. O objetivo é ser visível para o professor mesmo estando posicionado à frente da turma.

Contando com a colaboração de um professor de uma escola pública do DF, que se interessou pelo tema, a metodologia foi aplicada por ele, em uma de suas turmas e a observação feita por mim, na qualidade de pesquisador, será relatada a seguir. De forma a aproveitar a sequência de conteúdos utilizada por esse professor e não prejudicar o andamento de seu planejamento anual, o tema escolhido foi o de função afim, que fazia parte do rol de conteúdos previstos para o ano letivo.

A aplicação se deu em uma escola pública de ensino médio do Distrito Federal. Essa escola tem 17 turmas de $1^{\circ}$ ano. Uma turma foi escolhida aleatoriamente. Essa turma tem 32 alunos. A ApC foi aplicada em três aulas, sendo duas no primeiro dia e uma no segundo dia.

Antes da aula foi feita uma tabela para registrar a quantidade de alunos que escolheram como certa cada alternativa como no exemplo abaixo:

Tabela 5.1: Respostas das aplicações

\begin{tabular}{|l|l|l|l|l|l|l|}
\hline N $^{\circ}$ da questão & A & B & C & D & E & Abstenções \\
\hline 1 & & & & 27 & 1 & \\
\hline 2 & 3 & 21 & & & & 4 \\
\hline $2^{\prime}$ & & 28 & & & & \\
\hline 3 & 11 & 1 & & 16 & & \\
\hline $3^{\prime}$ & 2 & & & 27 & & \\
\hline 4 & & & 17 & & & \\
\hline $4^{\prime}$ & & & 27 & & & \\
\hline
\end{tabular}

As respostas após as discussões estão marcadas com aspas simples 


\begin{tabular}{|l|l|l|l|l|l|l|}
\hline $\mathrm{N}^{\circ}$ da questão & $\mathrm{A}$ & $\mathrm{B}$ & $\mathrm{C}$ & $\mathrm{D}$ & $\mathrm{E}$ & Abstenções \\
\hline 5 & & & & 21 & & \\
\hline 6 & 1 & 27 & 1 & & & 1 \\
\hline 7 & & 22 & & & & \\
\hline 7 & & 30 & & & & \\
\hline 8 & & 24 & & & & \\
\hline 9 & & & & & 2 & \\
\hline 10 & 18 & & & & & \\
\hline 11 & 8 & & & & & \\
\hline 11 & 14 & & & & & \\
\hline
\end{tabular}

Após a questão de número 6, o professor aplicador, conversou e sugeriu não registrar todas as respostas, apenas o gabarito de cada item, para melhorar o rendimento no quesito tempo. A sugestão foi aceita e efetivada a partir da questão 7. As questões 9 a 11 foram aplicadas na aula do dia posterior com um número menor de alunos. Observa-se aqui que o uso de dispositivos eletrônicos como os clickers facilitaria a obtenção das respostas e diminuiria o tempo gasto com essa aferição.

Além dessa tabela, foi montada outra tabela com as porcentagens $30 \%$ e $70 \%$ para qualquer quantidade de alunos presentes, para evitar que o professor perca tempo entre as questões conceituais calculando essas porcentagens. Por exemplo, no primeiro dia, estavam presentes 29 alunos. Trinta por cento de 29 é 8,7, ou seja, se a alternativa correta não tiver pelo menos 9 votos, então, pelo método, o professor deve ir para outra questão mais fácil, fato que ocorreu na questão 9, na qual os alunos ficaram muito confusos.

Em resumo, as quantidades ideais de acerto para que a discussão entre os alunos seja mais produtiva, estão no intervalo de 9 a 20. Porém nada impede que o professor faça, caso ache necessário, intervenções antes da discussão, ou até mesmo propiciar discussões mesmo com porcentagens fora do intervalo de $30 \%$ a $70 \%$. Fato que ocorreu durante a questão número 2, onde 21 alunos acertaram corretamente a questão, que seria o equivalente a $72,4 \%$ de acerto, mas mesmo assim o professor achou por bem fazer a discussão entre os alunos. A segunda votação comprova um aumento de cerca de $38 \%$ na quantidade de respostas corretas após a discussão. A literatura prevê aumentos de cerca de 14\% nas respostas corretas com o uso da ApC.

Para a exibição das questões foi utilizado um notebook, um datashow e o quadro branco. As imagens com as questões foram projetadas na metade do quadro branco, enquanto a outra metade serviu para o professor resolver algumas questões que achou necessário, mesmo após as discussões dos alunos.

Durante a aula, a sala estava organizada em fileiras, o que não foi mudado, pois a primeira resposta dada pelos alunos deve ser individual.

O teste de leitura serviu para que os alunos começassem a se familiarizar com o uso dos flashcards.

Segundo o professor que aplicou o método em sala de aula, algo que o fez refletir sobre o método foi o interesse e a participação dos alunos devido a alguns fatores. Segundo 
o professor aplicador:

A priori os alunos se mostraram bem animados, isso pode ser pela apresentação do projeto com o computador, que geralmente não é utilizado nas aulas de matemática, apesar de todas as salas de aula terem televisores, e ainda possuir projetores de vídeo. O interesse dos alunos pode também estar relacionado à competividade, pois cada aluno iria responder de forma individual, mas de imediato iria ver se acertou e poder se comparar com os outros. Também pode se relacionar com a pontuação, pois orientei que todos deveriam participar e estariam sendo avaliados de acordo não com o acerto aos itens, mas, sim, com sua efetiva participação.

Ele destacou ainda como pontos positivos primeiramente o fato de que o aluno já verifica se aprendeu no mesmo momento por ser um momento de aprendizagem e avaliação, diferente de quando se faz a apresentação do conteúdo de forma expositiva. Segundo, o caráter inovador, pois ele tem a impressão de que os alunos estão cansados das mesmas aulas, sempre do mesmo jeito, sentem falta da "modernização" da aula.

O professor conta também que, em uma aula posterior, um aluno solicitou que houvesse mais aulas com essa metodologia, o que mostra que ele se sentiu motivado pelo novo, pela mudança, pela construção do seu próprio conhecimento, conforme se extrai de sua fala, transcrita a seguir.

Isso me fez pensar nesse processo do interesse dos alunos pelo novo. O que precisa é ser avaliado que, conforme o tempo passe, ele volte a se desmotivar, sendo então o motivador do interesse do aluno não a dinâmica das aulas e sim a interna compreensão do aluno do interesse pela construção do conhecimento.

Como observador, pude fazer algumas constatações:

No início da aula, observei que os alunos não se sentiram muito confortáveis com o fato de expressarem a resposta com os flashcards, mas o desconforto passou após as questões do teste de leitura.

Durante as discussões, os alunos, inicialmente, não demonstraram interesse em discutir com os colegas sobre as suas respostas, principalmente na hora de procurar um colega com uma opinião diferente. Em alguns momentos, alguns tentaram interagir antes da primeira votação, que deveria ser individual. Isso é até natural, já que nunca tinham sido submetidos a esse método. Talvez tenha faltado uma intervenção do professor nesse momento. No entanto, acredito ser esse um processo que vai se ajustando à medida que todos experienciem essa nova prática.

Alguns alunos que estavam sentados no fundo da sala, evitaram o contato e o diálogo com os colegas, preferindo ficar sozinhos, mesmo após o estímulo do professor.

Na questão 3, metade da turma ficou dividida entre as alternativas A e D (correta), provavelmente pelo motivo de colocar o valor da imagem no lugar do domínio. Após a discussão, mais de $93 \%$ dos alunos escolheram a resposta correta. 
Durante a realização da questão 4 , constatei o seguinte:

Aluno 1: incomodado com o valor 0,2 , ele tentou resolver fazendo a proporção de 5 minutos para ficar arredondado o valor em $\mathrm{R} \$ 1,00$.

Nas questões 7 e 8, alguns alunos resolveram usando os valores das alternativas e testando uma a uma. Isso revela uma das deficiências das questões de múltipla escolha, sinalizando que o professor precisa cada vez mais se apropriar das técnicas de elaboração desse tipo de item.

Durante a realização da questão 5 , é importante ressaltar o que se segue.

Aluna 2: tinha escolhido a alternativa $\mathrm{B}$, na qual ela substituiu o valor 30 na fórmula, esquecendo-se de multiplicar por 10.

Aluno 3, ao explicar para a aluna 2, explicou que multiplicou o valor por 10 antes de efetuar a subtração, e, assim, a aluna pode perceber o erro.

Na questão 6, não houve o momento de discussão, pois $90 \%$ dos alunos escolheram a resposta certa, mas foi explicado pelo professor que naquele caso não iria precisar de nenhuma fórmula. Alguns alunos que responderam incorretamente, estavam tentando verificar se tinha alguma fórmula para inserir os valores do enunciado. Isso revela que alguns tentam automatizar a resolução de problemas de matemática, sem refletir sobre o que estão fazendo, buscando sempre uma fórmula pronta que possa resolver o problema.

O fato da disposição das carteiras estar em fileiras, muito usada nas aulas expositivas, prejudicou um pouco a interação entre os alunos.

As respostas de alguns alunos, já definidos pelos colegas como de bom rendimento em matemática, acabam influenciando os demais, que mudam suas respostas sem discutir. Alguns acabaram perguntando para o professor onde erraram. 


\section{Capítulo 6}

\section{Considerações Finais}

Neste trabalho apresentamos opções para a prática docente que podem tornar as aulas de matemática mais interessantes e motivadoras para os estudantes da educação básica. Para isso, discorremos sobre as metodologias ativas, evidenciando como elas podem contribuir para a mudança de postura do professor em sala de aula. A aprendizagem pelos colegas pode ser um bom ponto de partida, pois, mesmo um professor com pouca experiência com metodologias ativas, pode inserir, em seu planejamento, aulas de exercícios embasadas na ApC.

Após a aplicação de uma aula feita na perspectiva da ApC, foi observado o aumento do interesse dos alunos, muito maior durante as aulas com o uso da aprendizagem pelos colegas em relação às aulas anteriores, tradicionais e totalmente expositivas. Isso provavelmente se deve a dois fatores: às discussões entre os colegas proporcionada, intencionalmente pela metodologia, o que deixa a aula mais dinâmica; e à diminuição da parte teórica da aula, haja visto que grande parte da teoria foi entregue antes para que os alunos estudassem em casa. O ganho na quantidade de acertos em relação às questões de avaliação apresentadas foi bem expressivo, devido às discussões entre os alunos e à literatura pesquisada.

O caso pesquisado sugere que as metodologias ativas contribuem de forma ampla para melhorar o interesse dos alunos, e que as discussões entre os educandos contribuem muito para o aumento dos índices de respostas corretas na classe, favorecendo a melhoria do rendimento escolar.

Mesmo sendo mais usadas em universidades, o estudo aqui feito mostrou que há a possibilidade de se aplicar as metodologias ativas em outros segmentos como o ensino fundamental e médio. Porém, falta muita documentação em português, pois muitas das metodologias têm grande parte de suas referências ainda em inglês. Naturalmente, o caso estudado, pela limitação de tempo, se restringiu à ApC, sendo necessário aplicar os demais modelos de metodologias ativas em aulas de matemática. Quem sabe isso não provocaria melhoras nos indicadores de desempenho de nossos estudantes da educação básica em matemática, que hoje se encontram em níveis críticos, conforme resultados apontados pelo Sistema de Avaliação da Educação Básica e pela Prova Brasil.

A matemática é tratada e estigmatizada como uma disciplina muito difícil, pode 
ser visto em slogans de livros ou nome de cursos, tais como "matemática mais fácil", "matemática descomplicada". A maneira como a disciplina de matemática é ministrada só corrobora para aumentar esse mito. A matemática pode ser fácil, mas o docente por vezes fica tão atarefado com as obrigações administrativas da escola, e com a crença de que deve cumprir certa quantidade de conteúdos a qualquer custo, que não se interessa em relacionar a matemática com o cotidiano do aluno. Deixa de lado qualquer metodologia que possa demandar algum tempo para implementar. Um mudança de postura é realmente necessária e, nesse sentido, espera-se que este trabalho tenha mostrado que isso é possível, bastando se apropriar da metodologia e se adaptar às condições de infraestrutura que a escola disponibiliza. O importante é sair da inércia, de nossa zona de conforto, e fazer a mudança necessária que favoreça cada vez mais a aprendizagem de nossos estudantes. 


\section{Referências Bibliográficas}

ALBUQUERQUE, Irene de. Metodologia da matemática. Rio de Janeiro: Conquista, 1951.

ARAUJO I. S., MAZUR, E. Instrução pelos colegas e ensino sob medida: uma proposta para o engajamento dos alunos no processo de ensino aprendizagem de física. Caderno Brasileiro de Ensino de Física, v. 30, n. 2: p. 362-384, ago. 2013.

BARBOSA E. F., MOURA D. G. Metodologias ativas de aprendizagem na educação profissional e tecnológica publicado no B. Tec. Senac, Rio de Janeiro, v. 39, n.2, p.48-67, maio/ago. 2013. Acessado em <http://www.senac.br/media/42471/os_boletim_web_4.pdf> Acesso em: 27 de jul. 2016.

BARROWS, H. S. A taxonomy of problem based learning methods. Medical Education, v.20, p. 481-486, 1986.

BASSANEZI, R. C. Ensino-aprendizagem com modelagem matemática. São Paulo: Contexto, 2002.

BEAN, D. O que é Modelagem Matemática? Educação Matemática em Revista, ano 8, n. 9, 2001.

BIEMBENGUT, M. S.; HEIN, N. Modelagem matemática no ensino. 3; ed. São Paulo: Contexto, 2000.

BIEMBEnGUT, M. S. Revista de Educação em Ciência e Tecnologia, v.2, n.2, p.7-32, jul. 2009 BRASIL. Parâmetros Curriculares Nacionais (PCNs). Ensino Fundamental. Brasília: MEC/SEF, 1998.

CAMP, G. Problem-Based Learning: A Paradigm Shift or a Passing Fad? 
Medical Education Online, v.1, n. 2, 1996. Disponível em: ¡http://med-edonline.net/index.php/meo/article/view/4282i. Acesso em: 18 jun. 2016.

D'AMBrosiO, Beatriz S. Como ensinar matemática hoje? Temas e Debates. SBEM. Ano II. N2. Brasilia: p. 15-19. 1989.

DILLENBOURGH, P. et al. The evolution of research on collaborative learning. In: SPADA, E.; REIMAN, P. (Ed.). Learning in Humans and Machine: Towards an interdisciplinary learning science. Oxford: Elsevier, 1996.p. 189-211.

FERNANDES, D. Para uma teoria de avaliação formativa. Revista Portuguesa de Educação, 19(2), p. 21-50. 2006.

FERNANDES, S. A e TALIM, S. L. Tradução e validação do teste "Force Concept Inventory" XVIII Simpósio Nacional de Ensino de Física - SNEF 2009 - Vitória, ES. Disponível em <http://www.cienciamao.usp.br/dados/snef/_traducaoevalidacaodotest.trabalho.pdf $>$ Acesso em 27 de jul de 2016 .

HAGUENAUER, C. Metodologias e estratégias na educação à distância. Latec - UFRJ, Rio de Janeiro. Adaptado da entrevista concedida em janeiro de 2005 à Folha Dirigida. Disponível em $<$ http://www.latec.ufrj.br/portfolio/at/4\%20EAD\%20metodologias.pdf $>\quad$ Acesso em 27 de jul. 2016.

HOFFMANN, J. Avaliação: mito e desafio: Uma perspectiva construtivista. Porto Alegre:Mediação. 38a ed., 2007.

HOFFMANN, J. Avaliação Mediadora: Uma prática em construção da pré-escola à universidade. Porto Alegre, Mediação, 30a ed., 2010.

JORBA, J.; SANMARTÍ, N. A função pedagógica da avaliação. In: BALLESTER, M. et al. Avaliação como apoio à aprendizagem. Porto Alegre: Artmed, 2003.

LIBÂNEO, J. C. A Avaliação Escolar. In: LIBÂNEO, J. C. Didática. São Paulo: Cortez, 1994. p. 195-220.

LIBÂNEO, J. C. Adeus Professor Adeus Professora? Novas Exigências Educacionais e Profissão Docente. São Paulo - SP, Cortez 1998.

LUCKESI, C. C. Verificação ou Avaliação: O Que Pratica a Escola? Série Ideias 
n. 8. São Paulo: FDE, 1998 Páginas: 71-80.

LUCKESI, C. C. Avaliação da aprendizagem escolar. 14. ed. São Paulo: Cortez, 2002 .

LUCKESI, C. C. Perguntas e Respostas, 2006. Disponível em: $<$ http://www.luckesi.com.br/pergunda_e_respostas_questao_11.htm > Acesso em: 28 de fev. 2016.

LUCKESI, Cipriano. Faz sentido, no contexto da avaliação, servi-nos do termo "avaliação somativa"? Publicada em 04/09/2006. Disponível em: $<$ http://www.luckesi.com.br/pergunda_e_respostas_questao_11.htm $>$ Acesso em $20 / 10 / 2012$.

MAMEDE, S. Aprendizagem baseada em problemas: características, processos e racionalidade. In: MAMEDE, S.; PENAFORTE, J. (Org.). Aprendizagem baseada em problemas:anatomia de uma nova abordagem educacional. Fortaleza: Hucitec, 2001. p. $25-48$.

MATTHEWS, R.S.; COOPER, J.L.; DAVIDSON, N.; HAWKES, P. Building bridges between cooperative and collaborative learning . Change, v. 27, p. 35-40, 1995. Disponível em: ¡http://bgillmayberry.webs.com/Building\%20Bridges.pdfi. Acessado em 19 de fevereiro de 2016.

MAZUR, E. Peer Instruction : a revolução da aprendizagem ativa; tradução: Anatólio Laschuk. Porto Alegre: Penso, 2015.

MAZUR, E; WATKINS, J. Just-in-Time Teaching and Peer Instruction. In: SIMKINS, S.; MAIER, M. (Eds.). Just-In-Time Teaching: Across the Disciplines, Across the Academy Just-In-Time Teaching. 1. ed. Sterling: Stylus Publishing, 2010. p. 39-62.

OLIVEIRA FILHO, G. R. Bases Teóricas para a Implementação do Aprendizado Orientado por Problemas na Residência Médica em Anestesiologia. Revista Brasileira de Anestesiologia, v. 53, n. 2, p. 286-299, 2003.

PCN -Parâmetros Curriculares Nacionais. Disponível no endereço: $<$ http://portal.mec.gov.br/seb/arquivos/pdf/livro03.pdf $>$ acessado em 20 de junho de 2016.

PERRENOUD, Phillipe. Avaliação: da excelência à regularização das aprendizagens: entre duas lógicas. Porto Alegre, Artmed, 1998. 
PIAGET, Jean. Linguagem e Pensamento da Criança. Rio de Janeiro, Fundo de Cultura, 1959

PRENSKY, Marc. Digital natives, digital immigrants. On the Horizon. NCB University Press, v. 9, n. 5, 2001.

RABELO, M. L.. Avaliação Educacional: fundamentos, metodologia e aplicações no contexto brasileiro. Coleção Profmat. Rio de Janeiro: SBM, 2013.

SAKAI, M. H.; LIMA, G.Z. PBL: uma visão geral do método. Olho Mágico, Londrina, v. 2, n. 5/ 6, n. esp., 1996.

SCHIMIDT H. G. Problem-based learning: rationale and description. Med Educ, 1983;17:11-16.

SILBERMAN, M. Active learning; 101 strategies do teach any subject. Massachusetts; Ed. Allyn and Bacon; 1996.

SKOVSMOSE, O. Educação matemática crítica: a questão da democracia. 2 ed. São Paulo: Papirus, 2001. (coleção Perspectivas em Educação Matemática).

SADLER, Royce. Formative assessment and the design of isntructional systems. Instructional Science, n. 18, p. 119-144, June 1989.

TORRES, P. L.; ALCANTARA, P. R.; IRALA, E. A. F. Grupos de consenso: Uma proposta de aprendizagem colaborativa para o processo de ensino-aprendizagem. Revista Diálogo Educacional, Curitiba, v. 4, n.13, p.129-145, set./dez. 2004

TORRES, P. L.; IRALA, E. A. F. Aprendizagem Colaborativa: Teoria e Prática. Agrinho, Paraná, 2014. Disponível em: <http://www.agrinho.com.br/site/wpcontent/uploads/2014/09/2_03_Aprendizagem-colaborativa.pdf> Acesso em: 13 de julho de 2016.

VILLAS BOAS, B. M. F. Avaliação Formativa e Formação de Professores: Ainda um Desafio. Linhas Críticas, Brasília, v. 12, n. 22, p. 75-90, jun 2006. 


\section{Apêndice A}

\section{Material disponibilizado aos alunos}

Observe a receita a seguir:

Limonada suíça (4 pessoas)

- 2 limões médios

- 1/2 xícara (100 g) de açúcar

- 3 colheres (sopa) de leite condensado

- 3 xícaras $(720 \mathrm{~mL})$ de água

- Gelo

Modo de preparo (Preparo em 5 minutos)

1. Lave bem os limões, corte as extremidades fora e depois corte cada limão em 8 gomos.

2. Bata todos os ingredientes no liquidificador por 5 minutos. Coe e sirva imediatamente. 1

Letícia irá fazer essa receita para um jantar de família, que tem 16 pessoas. Qual será a quantidade de ingredientes que ela terá que comprar?

Diremos que Letícia terá que comprar tudo "na mesma proporção". O que isso significa? A receita diz que a quantidade rende para quatro pessoas, mas Letícia precisa fazer para 16 pessoas. Ela percebeu que a quantidade é quatro vezes maior. Para isso ela resolveu multiplicar todas as quantidades por quatro. Diremos que essas grandezas são proporcionais, ou seja, aumentam e diminuem "na mesma medida", na mesma proporção(multiplicadas pelo mesmo valor, que, no caso, é quatro). Nem todas as grandezas são proporcionais, como, por exemplo o tempo de bater a limonada no liquidificador, que é de 5 minutos. Esse tempo não precisa ser multiplicado por 4. Cada situação precisa ser analisada para ver quais grandezas são proporcionais ou não.

Observe a outra situação a seguir:

\footnotetext{
${ }^{1}$ Fonte da receita e da figura: <http://allrecipes.com.br/receita/2208/limonada-su-a.aspx>
} 
Um vendedor de rua ganha 10 reais por cada produto que vende. Se ele vender 10 produtos, irá ganhar 100 reais. Se ele vender 20 produtos, irá ganhar 200 reais, e assim por diante. A quantidade de produtos e o valor ganho com as vendas são grandezas proporcionais. Pode-se representar o lucro desse vendedor através de uma fórmula:

$L=10 . p$ em que a letra " $L$ " é o Lucro com as vendas e a letra " $p$ " representa a quantidade de produtos.

Observe que se ele vender o dobro de produtos, ele ganhará exatamente o dobro.

Em outra situação mais próxima da realidade, temos o caso de Juberval:

Juberval, um ótimo vendedor de sapatos, ganha um salário base mensal de $\mathrm{R} \$$ 700,00. Além desse salário base, ele também ganha uma comissão de R $\$ 10,00$ por cada par de sapato vendido, não importando o modelo ou valor do sapato.

Podemos dizer que o valor que esse vendedor ganha por mês é proporcional à quantidade de sapatos vendidos naquele mês? (ou seja, se vender o dobro, ele ganhará o dobro?)

Na verdade não, por causa do valor do salário base. Porém, também podemos estabelecer uma fórmula para o valor do salário de Juberval:

Sabe-se que a cada sapato vendido, ele ganha mais 10 reais de comissão. Assim, o valor ganho só com a comissão $(C)$ é proporcional à quantidade de pares de sapato que ele vende $(x)$, ou seja, $C=10 . x$ (Assim como no caso do vendedor de rua). No entanto, além desse valor, ele ainda ganha 700 reais como salário base. Então, pode-se representar o salário mensal de Juberval com a seguinte fórmula:

$$
S=10 \cdot x+700
$$

A importância dessa fórmula é que podemos prever quanto ele ganhará para qualquer quantidade de pares de sapatos que ele vender em um mês.

Com os três exemplos acima, podemos dizer que toda vez que em uma relação de duas quantidades, se aumentando uma delas a outra aumentar também, essa relação pode ser expressa por meio de uma fórmula do tipo:

$y=a x+b$,

em que o valor de "b" é sempre o valor inicial, como o valor de base do salário mensal de Juberval, e "a" é o valor do aumento, ou da diminuição, pois há casos em que o valor de y também poderá diminuir.

A função também pode ser representada na forma $\mathrm{f}(\mathrm{x})=\mathrm{ax}+\mathrm{b}$.

Observe a próxima situação:

A empresa de viagens Freeway fez a seguinte promoção para um grupo de formandos de um curso técnico:

Viagem de 10 dias para o Rio de Janeiro com entradas para os jogos olímpicos pelo valor base de $\mathrm{R} \$ 8.000,00$ com uma promoção imperdível de desconto de $\mathrm{R} \$ 50,00$ no valor base por cada pessoa que fechar o contrato.

Por exemplo, se forem 10 pessoas, o valor do desconto chegará a 50 x $10=500$ reais. Assim o valor do pacote de viagens sairá por $\mathrm{R} \$ 7.500,00$.

Essa situação pode ser descrita por uma função afim. Temos um valor inicial que 
nessa situação está sendo subtraído pelo valor do desconto.

Sabendo a fórmula, será possível determinar o valor da passagem para qualquer quantidade de estudantes.

Pode-se perguntar também:

Como a empresa possui um gasto médio de 5000 reais, caso essa promoção possa ser estendida para os familiares dos formandos, qual o valor máximo de pessoas que poderão fechar o contrato para que a empresa não tenha prejuízo?

E se a empresa considerar um lucro mínimo de 1000 reais? Qual será o valor mínimo do pacote por pessoa? E o valor máximo da quantidade de pessoas a fechar contrato?

O estudante Felipe quer saber quanto cada um pagará se forem todos os 30 alunos da turma? 